\title{
Canadian consensus guidelines for the optimal use of maraviroc in the treatment of HIV-infected adults
}

\author{
Anita Rachlis MD MEd FRCPC ${ }^{1}$, Marianne Harris MD CCFP², Richard Lalonde MD FRCPC ${ }^{3}$, \\ Stephen D Shafran MD FRCPC ${ }^{4}$, Cécile Tremblay MD FRCPC ${ }^{5}$, Mark A Wainberg PhD ${ }^{6}$, \\ Sharon Walmsley MD MSc FRCPC ${ }^{7}$
}

\begin{abstract}
A Rachlis, M Harris, R Lalonde, et al. Canadian consensus guidelines for the optimal use of maraviroc in the treatment of HIV-infected adults. Can J Infect Dis Med Microbiol 2010;21(4):159-172.
\end{abstract}

BACKGROUND AND OBJECTIVES: A Canadian group, consisting of six physicians and an HIV researcher with significant experience and knowledge in HIV management, reviewed the available data and developed guidelines for Canadian health care providers (who treat HIV infection) on the appropriate use of maraviroc (UK-427,857) in HIV-infected adults.

METHODS: Evidence from the published literature and conference presentations, as well as the expert opinions of the group members were considered and evaluated to develop the recommendations. Feedback on the draft recommendations was obtained from this core group, as well as from four other physicians across Canada with expertise in HIV treatment and experience with the use of maraviroc. The final recommendations represent the core group's consensus agreement once all feedback was considered.

RESULTS/CONCLUSIONS: Recommendations were developed to guide physicians and other health care providers in the optimal use of maraviroc. The recommendations were considered in light of the fact that the decision to include maraviroc in an antiretroviral regimen depends not only on issues that concern all antiretroviral agents, such as efficacy, safety, resistance and drug interactions, but also on the issue of viral tropism, which is unique to maraviroc and other CCR5 inhibitors.

Key Words: CCR5 receptor antagonist; Entry inhibitors; HIV; Maraviroc; Recommendations; Resistance; Treatment; Tropism

\section{Les lignes directrices canadiennes consensuelles sur l'utilisation optimale du maraviroc dans le traitement des adultes infectés par le VIH}

\begin{abstract}
HISTORIQUE ET OBJECTIFS : Un groupe canadien composé de six médecins et d'un chercheur sur le VIH possédant une expérience et des connaissances considérables dans la prise en charge du VIH, ont analysé les données disponibles et préparé des lignes directrices à l'intention des dispensateurs de soins canadiens (qui soignent l'infection à VIH) afin d'utiliser convenablement le maraviroc (UK-427,857) chez les patients infectés par le VIH.

MÉTHODOLOGIE : Le groupe a examiné et évalué les données probantes tirées des publications et des conférences et ont tenu compte de leur propre avis d'expert pour préparer les recommandations. Le groupe a commenté l'ébauche des recommandations et obtenu les commentaires de quatre autres médecins du Canada possédant des compétences dans le traitement du VIH et de l'expérience dans l'utilisation du maraviroc. Les recommandations définitives représentent l'entente consensuelle du groupe de base une fois tous les commentaires pris en compte.

RÉSULTATS ET CONCLUSIONS : Les recommandations ont été élaborées pour orienter les médecins et d'autres dispensateurs de soins quant à l'utilisation optimale du maraviroc. Elles ont été évaluées à la lumière du fait que la décision d'inclure le maraviroc dans la posologie antirétrovirale dépend non seulement de questions relatives à tous les antirétroviraux, telles que l'efficacité, l'innocuité, la résistance et les interactions des médicaments, mais également du tropisme viral, unique au maraviroc et à d'autres inhibiteurs de CCR5.
\end{abstract}


TABLE 1

Rating scheme for recommendations

\begin{tabular}{ll}
\hline Strength of recommendation & Quality of evidence for recommendation \\
\hline A: Strong & I: At least one randomized trial with clinical \\
B: Moderate & outcomes and/or validated laboratory \\
C: Optional & end points \\
& II: At least one well-designed, nonrandomized \\
& trial or observational cohort study with \\
& long-term clinical outcomes \\
& III: Expert opinion \\
\hline
\end{tabular}

Modified from reference 1

\section{INTRODUCTION TO CCR5 INHIBITORS AND MARAVIROC}

Novel antiretroviral (ARV) drug classes continue to play an important role in the treatment of HIV infection; regimens that include multiple drug classes are required to achieve full suppression of viral replication (plasma HIV-1 RNA [viral load] less than 50 copies $/ \mathrm{mL})(1,2)$. CCR5 inhibitors differ from other ARV agents because they act on the host cell rather than on the virus itself. CCR 5 inhibitors can block the process whereby HIV-1 enters the host cell (3-5). To gain access to human cells, the viral gp120 envelope glycoprotein first binds to the host cell surface antigen CD4, resulting in a conformational change in gp120. This change allows the virus to bind to either a CCR 5 or CXCR4 chemokine coreceptor on the cell surface, inducing additional conformational changes in the gp 41 transmembrane protein. The final entry step is virus-host cell fusion. The coreceptors are, therefore, crucial to viral entry into host cells, making CCR5 receptors compelling targets for therapeutic intervention because blockade of this step prevents viral infection.

Viral tropism is a property of HIV-1 that determines whether CCR5 or CXCR4 is used as a coreceptor. Some individuals are infected with HIV-1 strains that use only the CCR5 coreceptor (CCR5 tropic [R5] viruses), while others are infected with viruses that use only CXCR4 (CXCR4 tropic [X4] viruses). Some individuals may be infected with a mixture of $\mathrm{R} 5$ and $\mathrm{X} 4$ viruses (mixed tropic viruses) or virus strains that can use either the CCR5 or CXCR4 coreceptor (dual tropic viruses). Current tropism assays cannot distinguish between mixed and dual tropic viruses; therefore, these viruses are collectively known as dual/mixed tropic (D/M). Overall, CCR5 coreceptor use is significantly associated with higher CD4 cell counts and lower viral loads (6-8). The proportion of $\mathrm{D} / \mathrm{M}$ or $\mathrm{X} 4$ virus increases with decreasing CD4 cell count and increasing viral load. Reasons for these differences in the use of one coreceptor over the other are complex, and include virological and immunological factors, and even factors related to the microenvironment around the site of viral replication $(8,9)$.

Individuals infected with the R5 virus generally have slower disease progression than those infected with X4 virus (6). HIV-1 in treatment-naive patients is predominantly $\mathrm{R} 5$ (greater than $80 \%)(10-12)$. This finding is consistent across viral clades in at least one clinical trial (13). In treatment-experienced patients, X4 viruses are more common than in treatment-naive patients, and consist almost entirely of D/M viruses $(11,14)$. Pure CXCR4 tropism is rare $(6,10,14)$. Even in treatment-experienced patients, $48 \%$ to $67 \%$ are infected exclusively with R5 viruses $(10,12)$. Therefore, because a majority of patients harbour R5 viruses, the CCR 5 coreceptor is an appropriate target for blockade.
A natural phenomenon further supports CCR5 blockade as a therapeutic intervention. Some individuals have the CCR5 $\Delta 32$ allele, which encodes a shorter CCR5 molecule due to a 32 -base pair deletion in the allele (15-17). CCR $5 \Delta 32$ protein expression appears to be associated with suppressed CCR5 receptor activity, thereby restricting HIV infectivity (15). Individuals who are homozygous for CCR5 532 (approximately $1 \%$ of Caucasians) and, therefore, naturally lack CCR 5 cell surface coreceptors, appear to be resistant to R5 HIV-1 infection without a negative impact on immune status or general health (15-19). It should be noted that increased risks of both symptomatic infection and mortality from West Nile virus were reported in a small substudy of 17 patients homozygous for CCR $5 \Delta 32$ (20). Heterozygous individuals $(10 \%$ to $20 \%$ of Caucasians) may have partial resistance to R5 HIV-1 infection and exhibit delayed disease progression $(15-19,21)$. The reduced or absent expression of CCR 5 in individuals with the CCR5 $\Delta 32$ allele does not appear to have any other negative health consequences $(15,16)$.

A number of CCR5 receptor inhibitors are being or have been investigated for HIV-1 treatment. Of these, vicriviroc is in late-stage development, and only maraviroc is currently approved by Health Canada and available for clinical use. The present guidelines, therefore, focus on maraviroc. It should be noted that although all CCR5 inhibitors bind in the same area or 'pocket' of the CCR5 coreceptor molecule, they may occupy different regions of the pocket $(10,22)$ and may vary in other respects (eg, binding affinity leading to different efficacy, toxicity or resistance profiles).

\section{Maraviroc}

Maraviroc was identified as a drug candidate in a large-scale screening process for molecules that inhibit CCR 5 coreceptor binding. It selectively and reversibly binds to the CCR 5 receptor (23), inducing a conformational change that reduces the viral gp120 molecule's affinity for the coreceptor (allosteric inhibition) $(10,24)$. In vitro, maraviroc has broad-spectrum activity across R5 HIV-1 clades (25). Its role in HIV-2 blockade is currently unknown. Maraviroc has no activity against CCR2, which has the closest sequence identity to CCR5. Maraviroc is a true antagonist; therefore, it does not signal through the receptor after binding and, consequently, maraviroc does not appear to interfere with the wide-ranging role of chemokines in normal immune function $(25,26)$.

Maraviroc (formerly UK-427,857; Celsentri [ViiV Healthcare, USA]), in combination with other ARV agents, has been approved by Health Canada. It is indicated for use in treatment-experienced adult patients infected with R5 HIV-1 who have evidence of virus with resistance to multiple ARV agents (27).

\section{GUIDELINE GOAL}

The present guidelines are intended to provide recommendations to Canadian health care providers regarding the optimal use of maraviroc in adults with HIV-1 infection. The guidelines are not a substitute for the judgement of a physician experienced in treating HIV-infected patients.

The overarching goal of the treatment of HIV infection at all stages of the disease is to achieve sustained virological suppression (viral load of less than 50 copies/mL) $(1,2)$. To reach 
that goal, combination ARV therapy is necessary; maraviroc is a potential active contributor to ARV combinations.

Overall, the question of how maraviroc can be used optimally to achieve the goal of sustained viral suppression requires consideration of the same issues, as for other ARVs, including efficacy, safety, resistance and drug-drug interactions. However, maraviroc differs from other ARVs in two respects: viral tropism must be considered, and no commercial resistance testing is currently available for maraviroc. Data for maraviroc with respect to these issues are summarized in the following sections.

\section{CCR5 CORECEPTOR TROPISM}

\section{Efficacy of maraviroc based on HIV coreceptor tropism}

Maraviroc's safety and efficacy were assessed in a double-blind, placebo-controlled study (28) in treatment-experienced patients, primarily with D/M viral populations (1029 study). This study was also relevant to the concern that a CCR5 antagonist could trigger a coreceptor switch or select for X4 variants, both of which are associated with worse clinical outcomes. Patients had X4 or D/M tropic HIV-1, or indeterminate tropism, due to repeated assay failure. No significant differences were noted between the maraviroc and placebo recipients in viral load reductions, or in the percentage of patients with viral response (less than 50 copies $/ \mathrm{mL}$ ). CD4 cell count increases at 48 weeks were significantly greater in the maraviroc (twice a day [bid]) group versus the placebo group $\left(62\right.$ cells $/ \mathrm{mm}^{3}$ versus 36 cells $\left./ \mathrm{mm}^{3} ; \mathrm{P}=0.04\right)$. Post hoc analyses with a 'deep' sequencing methodology found that when X4 virus constituted less than $10 \%$ of the infecting virus population, virological response to maraviroc was greater than when the proportion of X4 virus was greater than $10 \%$ (29).

In the MOTIVATE studies of treatment-experienced patients (described in more detail in the 'Efficacy of Maraviroc' section), R5 tropism at baseline was associated with a virological and immunological benefit in the maraviroc arms (30). In patients with non-R5 virus at baseline, maraviroc treatment provided no virological benefit at week 48 . R5 virus at screening was associated with CD4 cell count increases in maraviroctreated patients $(\mathrm{P}=0.042)$ (31). Maraviroc-treated patients with non- $\mathrm{R} 5$ virus still had a larger increase in CD4 count at the time of virological failure versus those treated with placebo (30). Of the 1042 patients with R5 virus at screening, approximately $8 \%$ had a change in tropism to D/M or X4 between screening and baseline. These patients had lower baseline CD4 counts and higher baseline viral loads than those with R5 virus at baseline, consistent with other cohorts reported in the literature (6). More patients in the maraviroc arms had $\mathrm{D} / \mathrm{M}$ or $\mathrm{X} 4$ virus at the time of treatment failure (approximately two-thirds) versus the placebo arm $(n=4)(30)$.

In the MOTIVATE studies, time to treatment failure was approximately 30 days shorter in patients who failed with $\mathrm{D} / \mathrm{M}$ or $\mathrm{X} 4$ virus than in those who failed with $\mathrm{R} 5$ virus (30). A larger proportion of those who failed with $\mathrm{D} / \mathrm{M}$ or $\mathrm{X} 4$ virus did so before day 70 (62\% versus $37 \%$ of patients who failed with $\mathrm{R} 5$ virus). Of the patients who were followed for more than one month after their last study visit, 30 of 31 patients who had $\mathrm{D} / \mathrm{M}$ or X4 virus at last follow-up reverted to $\mathrm{R} 5$ virus.

A study (32) in treatment-naive patients found that a greater increase in CD4 cell count occurred in those who failed maraviroc treatment versus placebo regardless of viral tropism at failure (MERIT study - described in more detail in the 'Efficacy of Maraviroc' section). X4 virus was found in $31.3 \%$ of maraviroc-treated (300 mg bid) patients who had R5 virus at baseline. Among the patients who failed maraviroc treatment, tropism changes were less frequent (by approximately 50\%) in patients with clade $\mathrm{C}$ virus versus clade $\mathrm{B}$ or other clades. In a post hoc analysis of data from the MOTIVATE studies, the proportions of patients with X4 virus who had virological failure and a weighted optimized background therapy susceptibility score of 2 or greater were similar between the maraviroc and placebo arms (33).

\section{Association between tropism and baseline characteristics}

The association between HIV-1 coreceptor tropism and baseline characteristics was examined in 2585 treatment-experienced patients and 1277 treatment-naive patients (MOTIVATE and MERIT studies) (34). In treatment-experienced patients, 56\% had R 5 virus at screening, while $83 \%$ of treatment-naive patients had R5 virus, as measured by the standard Trofile (Monogram Biosciences Inc, USA) coreceptor tropism assay. R5 tropism was significantly associated with higher screening CD4 cell count and lower viral load in both treatment-experienced and treatmentnaive patients. A baseline CD4 cell count of 50 cells $/ \mathrm{mm}^{3}$ or greater, and viral load of less than 100,000 copies/mL were associated with a better virological response to maraviroc at week 48 in the MOTIVATE studies (treatment experienced) (35), and higher baseline CD4 counts were significant predictors of greater CD4 cell count increases in the MERIT study (treatment naive) (36). Therefore, tropism affected response to maraviroc via these baseline characteristics, regardless of previous ARV treatment experience.

Key findings: Maraviroc is not effective for the treatment of patients with a viral population that is predominantly non-R5. Lower viral load and higher CD4 cell count at baseline are associated with an increased probability of $R 5$ tropism. Treatment failure in patients whose viral tropism changes during treatment appears to be associated with the emergence of $X 4$ virus from a pre-existing reservoir rather than a tropism switch.

\section{Treatment-experienced adults}

\section{EFFICACY OF MARAVIROC}

Two large, double-blind, placebo-controlled, multicentre phase 3 studies, MOTIVATE-1 and MOTIVATE-2, demonstrated maraviroc's efficacy in treatment-experienced HIV-1 infected adults (37). These two studies of identical design included patients 16 years of age or older who at screening had plasma viral loads of 5000 copies/mL or greater and exclusively R5 HIV-1, and who had six or more months of exposure or documented resistance to drugs from at least three ARV classes. Patients were randomly assigned in a 2:2:1 ratio to treatment with maraviroc $150 \mathrm{mg}$ once daily (od), maraviroc $150 \mathrm{mg}$ bid or placebo - all in addition to an optimized background regimen selected by the investigator based on genotypic and phenotypic drug sensitivity testing. Maraviroc doses were adjusted, if necessary, based on potential pharmacokinetic interactions with the drugs in the optimized background regimen. The use of darunavir, etravirine and raltegravir was prohibited in the optimized background because they were investigational agents at the time, and tipranavir use was permitted during the latter part 


\section{TABLE 2}

Summary of key efficacy outcomes - pooled data from the MOTIVATE studies in treatment-experienced patients at 48 weeks (37)

\begin{tabular}{|c|c|c|c|c|}
\hline Parameter* & Maraviroc once daily $^{\dagger}$ & Maraviroc twice daily $^{\dagger}$ & Placebo $^{\dagger}$ & $\mathbf{P}^{\ddagger}$ \\
\hline Viral load data, $\mathrm{n}$ & 414 & 426 & 209 & \\
\hline Viral load mean change from baseline, $\log _{10}$ copies $/ \mathrm{mL}$ & -1.68 & -1.84 & -0.79 & $<0.001$ \\
\hline Difference from placebo group, $\log _{10}$ copies $/ \mathrm{mL}(97.5 \% \mathrm{Cl})$ & $-0.90(-1.17$ to -0.62$)$ & $-1.05(-1.33$ to -0.78$)$ & - & $<0.001$ \\
\hline Viral load <50 copies/mL, \% & 43 & 46 & 17 & $<0.001$ \\
\hline Viral load <400 copies/mL, \% & 52 & 56 & 22 & $<0.001$ \\
\hline Decrease in viral load from baseline of $\geq 1.0 \log _{10}$ or to $<400$ copies $/ \mathrm{mL}, \%$ & 58 & 63 & 29 & $<0.001$ \\
\hline CD4 count data, $\mathrm{n}$ & 407 & 418 & 206 & \\
\hline CD4 count mean change from baseline, cells $/ \mathrm{mm}^{3}$ & 116 & 124 & 61 & $<0.001$ \\
\hline Time to treatment failure ${ }^{\S}$, weeks & NA & NA & NA & $<0.001$ \\
\hline
\end{tabular}

*All patients who received at least one dose of study drug were included in the efficacy analysis. Missing values for patients who discontinued for any reason at or before week 48 were defined as equal to baseline; ${ }^{\dagger}$ All regimens included optimized background therapy; ${ }^{\ddagger}$ Pairwise comparisons: active treatment versus placebo; ${ }^{\S}$ Treatment failure was defined as one or more of the following four virological end points (confirmed by second consecutive measurements within 14 days): increase in HIV-1 RNA to at least three times baseline level at or after week 2; decrease of less than $0.5 \log _{10}$ copies $/ \mathrm{mL}$ at or after week 8; decrease of less than 1 log 10 copies $/ \mathrm{mL}$ at or after week 8 , following a decrease of $2.0 \log _{10}$ copies $/ \mathrm{mL}$ or greater; increase to 5000 copies $/ \mathrm{mL}$ or greater following levels of 400 copies/ $\mathrm{mL}$ or greater on two consecutive visits. NA Not available

of the study after drug-drug interaction data became available. Treatment for 48 weeks was planned, with an extension to 96 weeks. Patients were stratified at randomization for enfuvirtide use (yes/no) and viral load at screening (less than 100,000 copies/mL or 100,000 copies/mL or greater).

A total of 1049 patients received at least one dose of the study drug ( $\mathrm{n}=585$ in the MOTIVATE- 1 study, and $\mathrm{n}=464$ in the MOTIVATE-2 study) (37). Demographic and baseline characteristics were balanced between the two studies and among the treatment groups. In the combined analysis of the two studies, the mean viral loads at baseline were similar between treatment groups: $4.85 \log _{10}$ copies/mL to $4.86 \log _{10}$ copies $/ \mathrm{mL}$ in the maraviroc arms, and $4.86 \log _{10}$ copies $/ \mathrm{mL}$ in the placebo arm. The mean CD4 counts at baseline were also similar: 167 cells $/ \mathrm{mm}^{3}$ to 171 cells $/ \mathrm{mm}^{3}$ and 171 cells $/ \mathrm{mm}^{3}$, respectively. Overall, $94 \%$ of patients were infected with clade B HIV-1, and $8 \%$ of patients were heterozygous for the CCR5 532 genotype (35). Genotypic, phenotypic and overall susceptibility scores for the background ARV regimen were 2 or lower in $73 \%, 62 \%$ and $67 \%$ of patients, respectively, at screening (37). Overall susceptibility scores were derived from genotypic and phenotypic susceptibility data using a proprietary algorithm, except for enfuvirtide, for which the overall score was based solely on genotypic susceptibility.

The pooled efficacy results for the MOTIVATE-1 and the MOTIVATE-2 studies at 48 weeks, the primary end point for the studies, are provided in Table 2 (37). Maraviroc od and bid plus optimized background treatment were shown to be significantly more efficacious than placebo plus optimized background treatment in terms of viral load reductions and CD4 count increases. The viral load benefits were durable and continued to week 96 (CD4 count data not reported) (38). The proportions of patients with viral load reductions of $1 \log _{10}$ copies/mL or greater or to less than 400 copies $/ \mathrm{mL}$ were significantly greater in the maraviroc groups at 48 weeks ( $58 \%$ to $63 \%$ versus $29 \%$ in the placebo group, $\mathrm{P}<0.001$ ) (37). The maraviroc groups also had significantly longer times to treatment failure versus placebo. Results were similar in the two studies.

Patients in the maraviroc arms had greater immunological and virological benefits versus the placebo arm, regardless of whether resistance was identified at baseline: these benefits were seen in patients with triple class resistance at baseline and in patients with triple class experience but no resistance at baseline (39).

The maraviroc groups had better efficacy versus placebo in subgroup analyses at 48 weeks by sex, ethnicity (white or black), viral clade (B or non-B), heterozygous for the CCR5 432 genotype, viral load at screening (less than 100,000 copies/mL or 100,000 copies $/ \mathrm{mL}$ or greater), enfuvirtide use in the optimized background regimen (use versus nonuse), baseline CD4 count (less than 50 cells $/ \mathrm{mm}^{3}, 50$ cells $/ \mathrm{mm}^{3}$ to 100 cells $/ \mathrm{mm}^{3}$, 101 cells $/ \mathrm{mm}^{3}$ to 200 cells $/ \mathrm{mm}^{3}, 201$ cells $/ \mathrm{mm}^{3}$ to 350 cells $/ \mathrm{mm}^{3}$, and greater than 350 cells $/ \mathrm{mm}^{3}$ ), number of potentially active ARV drugs coadministered based on susceptibility scores, first use of selected background agents (enfuvirtide [received by $41 \%$ to $43 \%$ of patients), lopinavir/ritonavir [received by $29 \%$ to $36 \%$ of patients], tipranavir [received by $14 \%$ to $16 \%$ of patients]), and tropism at baseline (seven patients were misclassified as having R5 virus, mainly due to tropism assay sensitivity issues) (35). Significant associations were found between virological response at week 48 and the following baseline variables (ORs provided in Table 3): ethnicity (better response in white versus black populations; $\mathrm{P}<0.001$ ), viral clade (better response in non- $\mathrm{B}$ versus $\mathrm{B}$; $\mathrm{P}=0.004$ ), viral load at screening (better response in less than 100,000 copies $/ \mathrm{mL}$ versus 100,000 copies/mL or greater; $\mathrm{P}<0.001$ ), baseline CD4 count (better response in 50 cells $/ \mathrm{mm}^{3}$ or greater versus less than 50 cells $/ \mathrm{mm}^{3} ; \mathrm{P}<0.001$ ), overall susceptibility score (better response in scores greater than 1 versus 0 or 1 ; $\mathrm{P}=0.04$ ), and first-time use of enfuvirtide in optimized background regimen (better response with first-time enfuvirtide use versus enfuvirtide use [however, not the first time]; $\mathrm{P}<0.001$ ). It should be noted that the number of patients with clade non- $\mathrm{B}$ virus was relatively small (6\%), and it is, therefore, difficult to draw conclusions regarding the influence of viral clade on response to maraviroc therapy. In a post hoc analysis of data from the MOTIVATE studies, a baseline CD4 cell count of greater than 50 cells $/ \mathrm{mm}^{3}$ was one of the strongest predictors of virological response (33). Patients treated with maraviroc had better sustained virological efficacy versus placebo, even patients with no active agents in their optimized background regimen based on susceptibility scores. 
Patients in the MOTIVATE studies who were treated with maraviroc had substantial benefits versus patients treated with placebo, in terms of improvement in CD4 cell counts. In both studies, the least-squares mean changes in CD4 count from baseline to week 48 were consistently greater in the maraviroc groups versus the placebo groups, regardless of CD4 count and viral load at screening (35). This effect of maraviroc appeared to be independent of dose (31). Maraviroc-treated patients had earlier, more rapid and more persistent CD4 cell count increases versus placebo-treated patients. The larger CD4 cell count increases in the maraviroc groups relative to placebo occurred irrespective of whether viral suppression to less than 50 copies/mL was achieved. Larger, early and rapid CD8 cell count increases were also noted in the maraviroc arms versus the placebo arms $(\mathrm{P}<0.0001)$. The CD8 cell count subsequently decreased in all three arms, but did not return to baseline by week 48 in the maraviroc arms. Predictors of larger CD4 cell count increases were higher baseline CD4 cell count $(\mathrm{P}=0.0007)$, higher baseline viral load $(\mathrm{P}=0.0003)$, greater decreases in viral load at week $48(\mathrm{P}<0.0001)$, younger age $(\mathrm{P}<0.0001)$ and maraviroc treatment $(\mathrm{P}=0.002)$ - the last even after adjusting for viral load reduction.

On the other hand, in one uncontrolled study (40) of nine patients, the addition of maraviroc to a virologically suppressive ARV regimen for five months or more had no overall impact on their low CD4 cell count (approximately 200 cells $/ \mathrm{mm}^{3}$; $\mathrm{P}>0.39$ ), even though viral load remained suppressed.

Rates of treatment discontinuation in the MOTIVATE studies were higher in the placebo group $(68 \%)$ than in either the maraviroc od (39\%) or maraviroc bid (35\%) group (37). Lack of efficacy was the most common reason for discontinuation in all groups. Rates of discontinuation due to adverse events were low $(4 \%$ to $5 \%)$ and similar between treatment groups.

Key findings: Maraviroc, as part of an optimized ARV regimen, is efficacious in reducing viral load and increasing CD4 count in treatment-experienced patients with R5 HIV-1 infection.

\section{Optimization and number of active agents in the}

\section{background regimen}

Similar to other studies of newer ARVs (41-46) in patients with resistance to established agents, a positive association between the number of active agents in the background regimen and virological response was noted in the MOTIVATE studies. Other ARV drugs, when used for the first time, also demonstrated the benefit of including a fully active new agent in the background regimen along with maraviroc (35). A post hoc analysis found that a weighted optimized background therapy susceptibility score of 2 or higher was one of the strongest predictors of virological response to maraviroc in these treatment-experienced patients (33). Approximately $80 \%$ of patients with a weighted optimized background therapy susceptibility score of 2 or more had a virological response at week 48. The analysis excluded patients with nonvirological failure, and those whose baseline-optimized background regimen score did not accurately reflect the drugs received throughout randomized treatment. The definition of susceptibility used in the optimized background therapy susceptibility score was conservative: it assumed that the virus was either fully susceptible or fully resistant to a given ARV, and ritonavir
TABLE 3 Associations of baseline variables with viral load of less
than 50 copies/mL at week 48 (multivariate analysis) -
MOTIVATE studies (35)

\begin{tabular}{|c|c|c|}
\hline Baseline variable & $\mathbf{P}$ & OR $(95 \% \mathrm{Cl})$ \\
\hline Sex (male versus female) & 0.42 & $1.24(0.74-2.06)$ \\
\hline Ethnicity (white versus black populations) & $<0.001$ & $3.27(1.96-5.47)$ \\
\hline Virus clade (B versus non-B) & 0.004 & $0.33(0.14-0.77)$ \\
\hline $\begin{array}{l}\text { CCR } 5 \Delta 32 \text { genotype (homozygous versus } \\
\text { heterozygous) }\end{array}$ & 0.2 & $0.68(0.39-1.17)$ \\
\hline $\begin{array}{l}\text { Viral load at screening }(<100,000 \text { copies } / \mathrm{mL} \\
\text { versus } \geq 100,000 \text { copies } / \mathrm{mL})\end{array}$ & $<0.001$ & $2.13(1.53-2.97)$ \\
\hline $\begin{array}{l}\text { Baseline CD4 cell count }\left(<50 \text { cells } / \mathrm{mm}^{3}\right. \\
\text { versus } \geq 50 \text { cells } / \mathrm{mm}^{3} \text { ) }\end{array}$ & $<0.001$ & $0.25(0.15-0.42)$ \\
\hline $\begin{array}{l}\text { Genotypic susceptibility score } \\
(0 \text { to } 1 \text { versus }>1)\end{array}$ & 0.38 & $0.73(0.48-1.10)$ \\
\hline $\begin{array}{l}\text { Phenotypic susceptibility score } \\
(0 \text { to } 1 \text { versus }>1)\end{array}$ & 0.57 & $1.22(0.62-2.41)$ \\
\hline $\begin{array}{l}\text { Overall susceptibility score } \\
(0 \text { to } 1 \text { versus }>1)\end{array}$ & 0.04 & $0.45(0.22-0.90)$ \\
\hline Tropism at baseline (R5 versus non-R5) & 0.1 & $1.60(0.93-2.76)$ \\
\hline $\begin{array}{l}\text { Optimized background therapy containing } \\
\text { enfuvirtide (first use versus not first use) }\end{array}$ & $<0.001$ & $2.60(1.53-4.41)$ \\
\hline $\begin{array}{l}\text { Optimized background therapy containing } \\
\text { lopinavir-ritonavir (first use versus not first } \\
\text { use) }\end{array}$ & 0.44 & $1.58(0.77-3.25)$ \\
\hline $\begin{array}{l}\text { Optimized background therapy containing } \\
\text { tipranavir (first use versus not first use) }\end{array}$ & 0.52 & $1.14(0.52-2.52)$ \\
\hline
\end{tabular}

used to boost a protease inhibitor was excluded from scoring. For the overall susceptibility score, all active drugs were scored as 1.0; for the weighted score, active nucleoside/nucleotide reverse transcriptase inhibitors were scored as 0.5 , and other active agents were scored as 1.0.

Key findings: As noted in previous studies of new agents in treatment-experienced patients, at least two active agents in the background regimen provided a virological benefit in patients treated with maraviroc.

\section{Maraviroc dosing regimen}

At 24 weeks, subgroup analyses of the MOTIVATE studies found a viral suppression benefit for maraviroc dosing bid versus od dosing in three subgroups: screening viral load of 100,00 copies/mL or greater, baseline CD4 count of less than 50 cells $/ \mathrm{mm}^{3}$ and no active drug in the optimized background regimen (47). These data, along with population pharmacokinetic analyses that showed a higher proportion of patients in the bid groups of phase $2 \mathrm{~b} / 3$ studies with target maraviroc concentrations of $100 \mathrm{ng} / \mathrm{mL}$ or greater, which were associated with a greater likelihood of virological suppression $(48,49)$ and no evidence of increased safety risk (47), provided the basis for the bid dosing recommendation for maraviroc.

Key finding: Maraviroc bid dosing provides better viral suppression than od dosing.

\section{Treatment-naive adults}

Two phase 2a studies (A4001007 and A4001015) with similar designs were conducted in 63 asymptomatic HIV-1-infected adults who had R5 virus, viral loads of greater than 5000 copies $/ \mathrm{mL}$ and CD4 counts of greater than 250 cells $/ \mathrm{mm}^{3}$ (50). These patients 


\section{TABLE 4}

Summary of key efficacy outcomes - data from the MERIT study in treatment-naive patients at 48 weeks (intent-to-treat population) $(36,52,53)$

\begin{tabular}{|c|c|c|c|}
\hline Parameter* & $\begin{array}{l}\text { Maraviroc } 300 \text { mg bid } \\
\text { plus ZDV/lamivudine }\end{array}$ & $\begin{array}{l}\text { Efavirenz } 600 \mathrm{mg} \text { od } \\
\text { plus ZDV/lamivudine }\end{array}$ & $\begin{array}{c}\text { Lower bound } \\
97.5 \% \mathrm{Cl}\end{array}$ \\
\hline \multicolumn{4}{|c|}{ Inclusion of patients based on standard Trofile (Monogram Biosciences Inc [USA]) assay } \\
\hline Viral load data, $\mathrm{n}$ & 360 & 361 & \\
\hline Viral load at 48 weeks $<400$ copies $/ \mathrm{mL}, \%$ & 70.6 & 73.1 & $-9.5^{\dagger}$ \\
\hline Viral load at 48 weeks $<50$ copies $/ \mathrm{mL}, \%$ & 65.3 & 69.3 & $-10.9^{\dagger}$ \\
\hline Baseline viral load $<100,000$ copies/mL & 69.6 & 71.6 & - \\
\hline Baseline viral load $\geq 100,000$ copies $/ \mathrm{mL}$ & 59.6 & 66 & - \\
\hline CD4 data, $\mathrm{n}$ & 352 & 348 & \\
\hline Mean change in CD4 count from baseline, cells $/ \mathrm{mm}^{3}$ & 170 & 144 & $\begin{array}{c}95 \% \mathrm{Cl}: \\
7-46\end{array}$ \\
\hline \multicolumn{4}{|c|}{ Inclusion of patients based on more sensitive Trofile ES assay (retrospective analysis) } \\
\hline Viral load data, $\mathrm{n}$ & 311 & 303 & \\
\hline Viral load at 48 weeks <400 copies $/ \mathrm{mL}, \%$ & 73.3 & 72.3 & $-6.4^{\dagger}$ \\
\hline Viral load at 48 weeks $<50$ copies $/ \mathrm{mL}, \%$ & 68.5 & 68.3 & $-7.4^{\dagger}$ \\
\hline Baseline viral load $<100,000$ copies/mL & 71.8 & 72.1 & - \\
\hline Baseline viral load $\geq 100,000$ copies $/ \mathrm{mL}$ & 64.2 & 62.5 & - \\
\hline CD4 data, n & 303 & 291 & \\
\hline Mean change in CD4 count from baseline, cells $/ \mathrm{mm}^{3}$ & 174 & 144 & $\begin{array}{c}95 \% \mathrm{Cl}: \\
10-51\end{array}$ \\
\hline
\end{tabular}

*All patients who received at least one dose of the study drug were included in the efficacy analysis. Missing values were classified as failures/nonresponders; ${ }^{\dagger}$ Noninferiority margin for one-sided $97.5 \% \mathrm{Cl}$ is $-10 \%$ or greater; difference between treatment groups adjusted for randomization strata. bid Twice daily; od Once daily; ZDV Zidovudine

were either treatment naive, or had been off ARV treatment for at least eight weeks at the time of screening. Patients were randomly assigned to 10 days of monotherapy with either placebo or one of the following maraviroc doses: $25 \mathrm{mg}$ od, $100 \mathrm{mg}$ od or $300 \mathrm{mg}$ od; or $50 \mathrm{mg}$ bid, $100 \mathrm{mg}$ bid, $150 \mathrm{mg}$ bid (fasting and fed) or $300 \mathrm{mg}$ bid. In the analysis of the combined data from these studies, viral load reduction from baseline was greater in all maraviroc groups versus placebo. Viral load rebound was not immediate after the end of maraviroc treatment, with a median time to viral load nadir of 10 to 15 days after the end of treatment. At maraviroc doses of $100 \mathrm{mg}$ bid or more, all patients had viral load reductions of greater than $1 \log _{10}$ copies/mL at nadir, except one, identified later with a more sensitive assay, as having $\mathrm{D} / \mathrm{M}$ virus. No differences were noted in viral load reduction between bid and od maraviroc dosing, or between fed and fasted patients. Viral load reduction at day 11 appeared to correlate with systemic exposure to maraviroc (area under the $24 \mathrm{~h}$ plasma concentration curve) (51). Mean CD4 count changes from baseline were variable $\left(+5\right.$ cells $/ \mathrm{mm}^{3}$ to +150 cells $/ \mathrm{mm}^{3}$ for the maraviroc groups versus +2 cells $/ \mathrm{mm}^{3}$ to +31 cells $/ \mathrm{mm}^{3}$ for the placebo groups), and not correlated with viral load reductions or maraviroc dose.

An ongoing, double-blind, randomized phase 3 study (MERIT) has enrolled 721 treatment-naive patients 16 years of age or older with R5 HIV-1 infection, viral load of 2000 copies $/ \mathrm{mL}$ or greater, and no evidence of resistance to efavirenz, zidovudine or lamivudine at screening $(52,53)$. Randomization to treatment was $1: 1$ to either maraviroc $300 \mathrm{mg}$ bid plus zidovudine and lamivudine (Combivir, ViiV Healthcare, USA) (maraviroc arm), or efavirenz $600 \mathrm{mg}$ od plus zidovudine and lamivudine (efavirenz arm) for 96 weeks. The study originally included a maraviroc $300 \mathrm{mg}$ od (plus zidovudine and lamivudine) arm, but this arm was discontinued at 16 weeks when it failed to meet the protocol-defined noninferiority criteria (lower bounds of one-sided $97.5 \%$ CI for differences of more than $-10 \%$ in proportions of patients with viral load of less than 400 copies $/ \mathrm{mL}$ and less than 50 copies $/ \mathrm{mL}$ ) versus the efavirenz arm in a planned interim analysis. At randomization, patients were stratified by screening plasma viral load (less than 100,000 copies $/ \mathrm{mL}$ versus 100,000 copies $/ \mathrm{mL}$ or greater) and geographical region (northern versus southern hemisphere). The mean viral loads at baseline were similar between treatment groups: $4.86 \log _{10}$ copies $/ \mathrm{mL}$ and $4.88 \log _{10}$ copies $/ \mathrm{mL}$ in the maraviroc and efavirenz arms, respectively. The mean CD4 counts at baseline were also similar: 241 cells $/ \mathrm{mm}^{3}$ and 254 cells $/ \mathrm{mm}^{3}$, respectively, although the range was quite wide $\left(5 \mathrm{cells} / \mathrm{mm}^{3}\right.$ to 1422 cells $/ \mathrm{mm}^{3}$ ).

The efficacy results from the MERIT study were analyzed twice: the first set of analyses was based on a population that had tropism determined at screening using the standard Trofile assay available at the time, and the second set was a retrospective analysis that only included patients with CCR5 viral tropism established using a more sensitive assay (Enhanced Sensitivity Trofile assay or Trofile ES), which became available only later (53). The standard Trofile assay is no longer available, so the reanalysis was considered important to inform current clinical practice. Use of the Trofile ES assay to re-evaluate tropism at screening reclassified $15 \%$ of the 721 patients in the trial as having non- $\mathrm{R} 5$ virus.

In the original analysis (using the standard Trofile population), fewer patients with non-R5 HIV-1 were identified, and the noninferiority of maraviroc was demonstrated only in the proportion of patients with a viral load of less than 400 copies $/ \mathrm{mL}$ at week 48 (Table 4), and not in either of the per protocol comparisons, which excluded the patients with non-R5 virus, as determined by the less sensitive assay (52). Maraviroc exposure during the study and CCR 5 tropism at baseline (7\% of patients had R5 virus at screening, and non-R5 at baseline) were the 
most significant predictors of viral load suppression (viral load of less than 50 copies $/ \mathrm{mL}$ ) (54).

In the second set of analyses, using the population that had R5 virus, as determined by the Trofile ES assay (Trofile ES population), the maraviroc arm was comparable with the efavirenz arm in the proportions of patients with viral loads of less than 400 copies/mL and less than 50 copies/mL (intentto-treat analysis) at week 48 (Table 4) (53). Because this reanalysis using the Trofile ES population was conducted retrospectively, these data can only be considered descriptive, and conclusions should be drawn cautiously. Comparable virological responses were seen with maraviroc and efavirenz in both baseline viral load subgroups (less than 100,000 copies/mL versus 100,000 copies $/ \mathrm{mL}$ or greater) in both the standard Trofile and Trofile ES populations (Table 4).

The overall rates of discontinuation in the MERIT study were similar in the two treatment groups, but more patients treated with maraviroc withdrew due to lack of efficacy $(11.9 \%$ versus $4.2 \%$ of patients treated with efavirenz) (standard Trofile population) (52). In contrast, more withdrawals due to adverse events (primarily central nervous system symptoms or rash) occurred in the efavirenz arm (13.6\% versus $4.2 \%$ in the maraviroc arm).

The treatment-naive patients in the MERIT study who received maraviroc also had CD4 cell count benefits. CD4 cell counts increased from baseline significantly more in the maraviroc arm than in the efavirenz arm in both the Trofile and Trofile ES populations (Table 4) (53). This difference was apparent as early as week 8 (32), and remained after adjustment for change in viral load (36). CD4 cell count increases in the maraviroc arm were early, rapid and consistently greater than in the efavirenz arm. This early, rapid rise in CD4 cell counts was mirrored in CD8 cell counts in the maraviroc arm, which initially rose and then fell but remained above baseline, while CD8 cell counts decreased in the efavirenz group between baseline and week 48 (median +28 CD 8 cells $/ \mathrm{mm}^{3}$ versus -110 CD8 cells $/ \mathrm{mm}^{3}$ at week 48 , respectively; $\mathrm{P}=0.0001$ for the differences in effect of treatment over time). Significant predictors of greater CD4 cell count increases in the MERIT study by multivariate regression analysis were higher baseline CD4 cell counts $(\mathrm{P}=0.0005)$, larger decreases in viral load at week 48 $(\mathrm{P}<0.0001)$, and inclusion of maraviroc in the study-defined treatment regimen $(\mathrm{P}<0.0001$ versus inclusion of efavirenz).

Key findings: In treatment-naive patients, the noninferiority or benefit of maraviroc versus efavirenz in terms of viral suppression has not yet been clearly demonstrated. This result may be due to inaccurate patient selection based on lower sensitivity tropism testing, which incorrectly categorized some viruses. The CD4 cell count benefits of maraviroc therapy appear to be promising, but the clinical significance of this greater CD4 cell count response versus that seen with efavirenz has yet to be determined.

\section{RESISTANCE TO MARAVIROC AND OTHER REASONS FOR TREATMENT FAILURE}

Unlike ARV agents from other classes, CCR 5 antagonists bind to a host protein (the CCR 5 coreceptor), and the drug binding site is not altered by viral mutations. However, changes in the viral envelope may affect binding of maraviroc to the coreceptor, or may allow the virus to use the maraviroc-bound conformation of CCR5 to enter the host cell.
The third variable (V3) loop area of the viral envelope gp120 is critical to the interaction of the virus with the CCR5 coreceptor. Genetic sequencing of the V3 loop may predict response to maraviroc (55). In the MOTIVATE studies, no patient had maraviroc-resistant HIV-1 at baseline. In a preliminary analysis, one-third of patients who failed treatment with $\mathrm{R} 5$ virus showed phenotypic resistance to maraviroc and had mutations in the V3 loop (56). Amino acid substitutions were also found in gp120, outside of the V3 loop, but the significance of these substitutions is not currently understood. In vitro, mutations at $\mathrm{A} 316 \mathrm{~T}$ and $\mathrm{I} 323 \mathrm{~V}$ in the $\mathrm{V} 3$ loop confer resistance to maraviroc (57); because these mutations are different from those reported for other CCR5 inhibitors $(22,58)$, cross-resistance between these agents is not expected to be an issue. However, the patterns of genotypic changes that confer resistance to maraviroc and other CCR5 antagonists are not well characterized; therefore, phenotypic assays are usually used to predict antiviral activity of these agents.

In a later analysis of 333 patients in the MOTIVATE studies who received maraviroc and whose optimized background therapy remained unchanged (59), maraviroc phenotypic resistance was found in one-third of R5 virological failures overall including approximately one-half ( 16 of 30 ) of the R5 virological failures on functional maraviroc monotherapy. This outcome suggests a relatively high barrier to maraviroc resistance, and that treatment failure in these cases was due to other factors.

Because maraviroc selectively inhibits $\mathrm{R} 5$ virus, a change in the tropism of the predominant viral population can also cause a lack of response to and treatment failure with ARV regimens containing maraviroc. These outcomes are usually the result of emergence or unmasking of pre-existing D/M or X4 HIV, rather than as a result of mutation of $\mathrm{R} 5$ to $\mathrm{X} 4$ virus under selective pressure of maraviroc. In a study of HIV-infected patients who received 10 days of maraviroc as monotherapy, two patients who had R5 virus at baseline had D/M virus after treatment $(60,61)$, which was shown to have most likely arisen from a reservoir of $\mathrm{R} 5 \mathrm{X} 4$ variants that existed before treatment (60-62). In samples from the MOTIVATE studies, envelope protein clonal analysis detected pre-existing X4 virus in both the maraviroc-treated and placebo-treated patients who failed treatment (63). Similarly, a prospective cohort study (64) of 26 patients found only rare changes in tropism during viral suppression. Because the $\mathrm{D} / \mathrm{M}$ or $\mathrm{X} 4$ virus pre-exists, time to treatment failure is shorter, as noted in the MOTIVATE trials (30), than when maraviroc resistance is selected by de novo mutation of R5 to X4. After cessation of treatment with maraviroc, selective pressure on the $\mathrm{R} 5$ virus is removed, which enables it to re-emerge as the dominant virus $(30,65,66)$. The timing of this re-emergence seen in the MOTIVATE studies was approximately 16 weeks, which is similar to the time frame for emergence of lamivudine (3TC) and enfuvirtide resistance after withdrawal of these ARVs.

Lack of response to a regimen containing maraviroc may also arise as a result of resistance to other agents in the treatment regimen, as is the case with other new ARV agents (41-46). For example, in the MERIT study, the M184V mutation (associated with resistance to lamivudine) was the most common mutation found among patients in the maraviroc arm who discontinued treatment due to lack of efficacy: 19 of 19 patients with D/M or $\mathrm{X} 4$ virus at failure, and 10 of 22 patients with R5 at failure (32). 
Phenotypic or genotypic resistance to maraviroc was uncommon in patients with $\mathrm{R} 5$ virus at failure, suggesting that treatment failure was associated with resistance to $3 \mathrm{TC}$ rather than to maraviroc. In the MOTIVATE studies, virological failure was seen in $37.5 \%$ (30 of 80 ) of patients with less than one active agent in their background regimen, compared with $12.7 \%$ (32 of 251) of those whose background regimen contained one or more active agents (56).

Finally, lack of response to maraviroc-containing regimens may be a result of suboptimal maraviroc exposure due to inadequate adherence, dosing or pharmacokinetic issues. Low maraviroc plasma levels due to nonadherence were associated with treatment failure in treatment-naive patients in the MERIT study (32). Maraviroc dosing, pharmacokinetics and drug-drug interactions are addressed in the 'Maraviroc Pharmacokinetics and Drug-Drug Interactions' section.

\section{Resistance testing}

Currently, neither phenotypic nor genotypic resistance testing for CCR 5 antagonists is commercially available. Because resistance to CCR5 antagonists is likely to involve the envelope gene, tests to evaluate resistance will have to focus on genotypic or phenotypic evaluation of this gene. Efforts are being made to characterize the regions in the viral envelope responsible for resistance; however, to date, no unique mutation patterns have been identified.

Key findings: The mechanism of resistance to maraviroc and other CCR5 antagonists is unique among ARVs, and treatment failure with maraviroc is not necessarily due to maraviroc resistance. No commercial test for maraviroc resistance is currently available.

\section{TROPISM TESTING}

The enhanced sensitivity Trofile assay (Trofile ES) has been validated, with an ability to detect X4 clones at levels as low as $0.3 \%$ versus $10 \%$ with the original Trofile assay (67). Regardless of improved test sensitivity, current methodologies cannot reliably provide tropism results in patients with viral loads of less than 1000 copies/mL (68).

Efforts are underway to develop genotyping techniques that use ultrasensitive sequencing technology and enhanced predictive algorithms to determine viral tropism (69). Important progress in this regard, based on sequencing of the V3 loop within the viral envelope, has been reported (55). This analysis is a retrospective comparison of V3 loop genotyping against results obtained with the Trofile ES assay using samples from the MERIT trial, and shows near equivalence between the two methods.

However, for the time being, the enhanced sensitivity Trofile assay is the only test available to determine viral tropism in patients potentially eligible for treatment with CCR5 antagonists.

Key findings: While the greater sensitivity of the Trofile ES assay allows for more accurate assessment of viral tropism than the earlier version of the assay, other methods with even more sensitivity could be developed in the future.

\section{Timing of treatment initiation following tropism testing}

The MERIT study was designed to include treatment-naive patients with R5 virus. In fact, 24 patients (13 of 360 [4\%]) in the maraviroc arm) had a change in viral tropism from R5 to $\mathrm{D} / \mathrm{M}$ between screening and baseline (a period of up to six weeks) (32). Virological response to maraviroc treatment (less than 50 copies $/ \mathrm{mL}$ ) occurred much more frequently in patients with R5 virus (68.0\%) compared with those with D/M virus $(7.1 \%)$.

Key finding: A patient's viral coreceptor tropism may change, even over relatively short periods of time. Therefore, the results of tropism testing performed previously are not necessarily relevant to a patient's current situation.

\section{SAFETY OF MARAVIROC}

Adverse events and concomitant conditions

Clinical trial data in more than 1900 patientss, including 1349 HIV-1-infected individuals, have shown that maraviroc is well tolerated $(27,28,37,52)$. The most common treatment-related adverse events in the MOTIVATE and MERIT clinical trials were diarrhea, dizziness, nausea, fatigue and headache $(52,70)$. Most adverse events were mild to moderate in severity (27).

In treatment-experienced patients, maraviroc had a safety profile similar to placebo $(28,37,70)$, despite the fact that, in the MOTIVATE studies, exposure to maraviroc greatly exceeded exposure to placebo (300 to 309 patient-years for maraviroc versus 111 patient-years for placebo) due to the imbalance in treatment discontinuations $(68 \%$ in the placebo group versus 39\% and 35\% in the maraviroc od and bid arms, respectively) (37). Also, treatment-related adverse event incidence, discontinuations due to treatment-related adverse events, serious adverse event incidence and death rates were similar among treatment groups, with no discernible pattern of differences. The latter analyses were not adjusted for drug exposure.

The safety profile of maraviroc in treatment-naive patients is similar to that in treatment-experienced patients. Treatmentnaive patients treated with maraviroc had a better safety profile overall than those treated with efavirenz, with fewer grade 3/4 adverse events and fewer discontinuations due to adverse events (52).

\section{Category $\mathrm{C}$ events}

Theoretically, chronic CCR5 inhibition could affect CCR5mediated pathways in the immune response to some pathogens and malignancies (26). To date, these potential immunomodulatory effects have not been observed with maraviroc treatment. Maraviroc treatment was not associated with an increase in category $\mathrm{C}$ (ie, AIDS defining) events in the MOTIVATE studies of treatment-experienced patients at 48 or 96 weeks $(37,38,70)$, or in the MERIT study of treatment-naive patients (52). In the Saag et al (28) study (treatment-experienced patients), more category $\mathrm{C}$ events were reported in patients treated with maraviroc od $(9.5 \%)$ versus placebo $(3.2 \%)$ or maraviroc bid (4.9\%), although this difference was not considered to be significant by the authors of the publication.

The time to category $\mathrm{C}$ event occurrence was significantly increased in the maraviroc arms versus the placebo arms $(\mathrm{P}=0.042)$ in the MOTIVATE studies' treatment-experienced patients (31). This difference may be related to more effective virological suppression or greater CD4 cell count gains with maraviroc or both. Higher on-treatment CD4 counts were associated with a longer time to category $\mathrm{C}$ events in a post hoc 
analysis of the MERIT study (treatment-naive patients) (36). No relationship between the increased number of category $C$ events and changes in viral tropism from R 5 to X4 during treatment was found in maraviroc-treated patients in the MOTIVATE studies (30).

Maraviroc treatment was associated with longer time to a category $\mathrm{C}$ event using a multivariate analysis, as were lower baseline viral loads, higher CD4 counts on treatment and viral load of less than 50 copies/mL at week 48 (36).

\section{Hepatic adverse events}

The potential for a CCR 5 antagonist class effect of hepatotoxicity was raised by several cases of severe hepatotoxicity in aplaviroc trials - the development of this experimental CCR 5 antagonist was halted due to this association (71). A detailed examination of these data determined that aplaviroc's hepatotoxic effect was likely an effect of the molecule, rather than its mechanism of action. In all maraviroc clinical studies, only isolated cases of severe liver enzyme abnormalities or hepatic adverse events were observed, with no evidence of a relationship with maraviroc (72). Severe hepatotoxicity as indicated by liver enzyme or bilirubin results was not more frequent in the maraviroc groups versus the placebo groups in either the overall or subgroup analyses of the MOTIVATE studies $(35,37)$. Notably, patients with hepatitis B or hepatitis C coinfection were not at a greater risk for liver enzyme abnormalities when treated with maraviroc in clinical trials (72). Based on clinical trial data overall, maraviroc does not appear to be associated with significant hepatotoxicity.

\section{Malignancies}

Initial concerns about potential CCR 5 antagonist class effects raised by malignancy data for vicriviroc, another experimental CCR5 antagonist, in the ACTG 5211 study appear to be unwarranted based on further analysis (73) and the following data for maraviroc. Malignancies were not increased among patients treated with maraviroc versus the comparator in clinical trials (27). In treatment-experienced patients, category $\mathrm{C}$ malignancies did not have a higher incidence in the maraviroc arms (three of 300 patients for maraviroc od, four of 426 patients for maraviroc bid and five of 209 patients for placebo in the MOTIVATE studies at week 48; none reported in the Saag et al study $[28,37,38])$. In the MOTIVATE studies, all-category malignancy rates were lower in the maraviroc groups than in the placebo group ( 8.8 to 9.3 per 100 patient-years versus 13.3 per 100 patient-years, respectively at week 48) (70). At the end of blinded therapy (between 48 and 96 weeks), the exposure-adjusted incidence of malignancy was lower than at 48 weeks ( 3.5 to 3.6 per 100 patient-years in the maraviroc groups versus 7.1 per 100 patient-years in the placebo group), and the exposure-adjusted incidence of malignancies remained lower in the maraviroc groups versus the placebo group (38). In the Saag et al (28) study, one patient per treatment group had a malignancy, and none had lymphomas. It should be noted that the follow-up period for malignancy in these studies, although considerable at 96 weeks, is still relatively short.

\section{Cardiovascular effects}

In vitro data suggest a role for CCR 5 receptors in vasoconstriction, and blockade of this response with maraviroc (74). The dose-limiting postural hypotension seen in phase 1 studies of healthy volunteers occurred in maraviroc-treated patients at rates greater than in placebo-treated patients, and only at doses of $600 \mathrm{mg}$ or greater (75). At these higher doses, from double to triple the clinical dose, the hemodynamic response maintaining blood pressure was not fully compensated (76). At the lower maraviroc doses of $150 \mathrm{mg}$ od and bid used in the MOTIVATE studies, reports of orthostatic hypotension were rare (70). Therefore, the mild vasodilatory effect of maraviroc does not seem to be clinically significant at the usual recommended dose.

In phase 3 clinical trials, a low incidence of myocardial ischemia and/or myocardial infarction in patients receiving maraviroc was observed, consistent with background rates, and occurred primarily in patients with pre-existing cardiac disease or cardiac risk factors (27). No evidence of a clinically relevant effect of maraviroc on the QTc interval was found in healthy patients following single doses of maraviroc of up to $900 \mathrm{mg}$ (77).

\section{Lipids}

Among treatment-naive patients in the MERIT study (52), maraviroc had a more benign effect on serum lipids than efavirenz. Total cholesterol, low-density lipoprotein cholesterol and triglyceride levels were significantly higher at 48 weeks in the efavirenz arm than in the maraviroc arm $(\mathrm{P}<0.0001$ for all except triglycerides $[\mathrm{P}=0.0002])(78)$, although high-density lipoprotein cholesterol was also higher with efavirenz $(\mathrm{P}<0.0001)$. More patients treated with efavirenz had lipid level increases from baseline to above the recommended United States National Cholesterol Education Program guideline levels. A small but significantly greater decrease in the total cholesterol/high-density lipoprotein ratio from baseline was observed in the maraviroc arm versus the efavirenz arm $(-0.54$ versus -0.43 , respectively; $\mathrm{P}=0.005)$.

\section{Infections}

Rates of upper respiratory tract and herpes virus infections were higher in maraviroc-treated patients, while rates of pneumonia were lower compared with patients treated with placebo in phase 3 studies (27). However, the overall incidence and severity of infections and AIDS-defining infections were similar in maraviroc and placebo arms. The same was noted in the combined MOTIVATE studies at week 96 (79).

The greater incidence of esophageal candidiasis in the maraviroc od arm at week 48 of the MOTIVATE studies $(n=12$ versus $n=3$ in the maraviroc bid arm and $n=2$ in the placebo arm; $\mathrm{P}=0.04$ for the three-way comparison) (37) should be interpreted cautiously because the analysis was post hoc and not adjusted for exposure.

\section{Safety in other patient populations}

Animal data indicate no effects of maraviroc on embryo-fetal development (27). A slight increase in motor activity at high doses of maraviroc was noted in male offspring of maraviroctreated rats at weaning and in the same offspring as adults. Development of these offspring was not affected by maternal administration of maraviroc.

No substantial human data on exposure during pregnancy are currently available. The drug has been assigned a pregnancy 
category B by the United States Food and Drug Administration, meaning that animal studies have revealed no risk to the fetus; however, adequate and well-controlled studies in pregnant women are not available (80).

Regarding breastfeeding, no human data are currently available (27). Rat studies show extensive secretion of maraviroc into milk.

Subjects not infected with HIV, but with mild and moderate hepatic impairment had area under the curve (AUC) values for maraviroc that were $25 \%$ and $46 \%$ higher, respectively, than patients with normal hepatic function (81). Differences in peak concentration $\left(\mathrm{C}_{\max }\right)$ were smaller $(11 \%$ and $32 \%$ higher for mild and moderate impairment, respectively, versus normal function). The maraviroc clearance/bioavailability ratio decreased with increasing hepatic impairment, although the difference between normal function and mild hepatic impairment was minimal.

Maraviroc safety and efficacy have not been studied in patients with renal impairment. Renal clearance accounts for less than $25 \%$ of the total clearance of maraviroc; however, in the presence of metabolic inhibitors, renal clearance could account for up to $70 \%$ of the total clearance (27).

Maraviroc has not been studied in patients younger than 16 years of age, and limited data are available for patients 65 years of age and older (27).

Key findings: Maraviroc use is well tolerated and safe in patients with HIV-1 infection. Its safety profile is similar to that of placebo, and similar to or better than that of efavirenz as part of an ARV regimen. No apparent relationship between maraviroc and hepatotoxicity or malignancy was noted in clinical trials.

\section{MARAVIROC PHARMACOKINETICS AND DRUG-DRUG INTERACTIONS}

Maraviroc pharmacokinetics and exposures are similar between HIV-1-infected patients and healthy volunteers $(27,49)$. Maraviroc plasma concentrations peak $0.5 \mathrm{~h}$ to $4 \mathrm{~h}$ after oral dosing (27). Food had no substantial impact on absorption (27), and efficacy after 10 days of monotherapy was unaffected by food (82). The terminal half-life of maraviroc was $14 \mathrm{~h}$ to $18 \mathrm{~h}$ in healthy volunteers (27).

Maraviroc has one of the highest female genital tract exposures relative to plasma of any ARV (83). In a study of 12 healthy female volunteers after seven days of maraviroc $300 \mathrm{mg}$ bid dosing, maraviroc concentrations in the genital tract were 10-fold higher than the concentration that achieves $90 \%$ inhibition $\left(\mathrm{IC}_{90}\right)$ in all patients by $2 \mathrm{~h}$. The clinical implications of these findings are unclear.

Maraviroc is largely metabolized by the cytochrome P450 (CYP) 3A4 isoenzyme (27). Maraviroc does not inhibit the seven major cytochrome P450 isoenzymes including CYP3A4; therefore, it is unlikely to affect the pharmacokinetics of coadministered drugs that are metabolized by these enzymes (84). However, maraviroc is a substrate of CYP3A4 and P-glycoprotein (P-gp) (27) and, therefore, its pharmacokinetics are likely to be affected by inhibitors and inducers of these enzymes/transporters. Data for ARVs that may be used with maraviroc confirm this prediction: CYP3A4/P-gp inhibitors (lopinavir/ritonavir, ritonavir, saquinavir, atazanavir and darunavir/ritonavir) increased maraviroc exposure $\left(\mathrm{C}_{\max }\right.$ and AUC), and the CYP3A4 inducer efavirenz decreased maraviroc exposure ( $\mathrm{C}_{\max }$ and $\mathrm{AUC}$ ) (27). These exposure effects can be corrected by dose adjustment of maraviroc (84). Tipranavir/ ritonavir, a CYP3A4 inhibitor and P-gp inducer, did not affect the steady state pharmacokinetics of maraviroc (27). Pharmacokinetic studies of zidovudine and lamivudine found no effect of maraviroc. The pharmacokinetics of various combinations of ARVs were studied when coadministered with maraviroc. Table 5 summarizes the interactions of other ARVs with maraviroc, and the dose adjustments recommended by the manufacturer.

Because a small proportion of maraviroc is secreted renally (20\%), no significant interactions with inhibitors and substrates of renal secretion were expected $(27,84)$. The clinical data for the pharmacokinetics of coadministered trimethoprim and tenofovir are consistent with this assumption. However, in the presence of metabolic inhibitors, renal clearance could account for up to $70 \%$ of total clearance (27); therefore, inhibitors and substrates of renal secretion would be expected to have a greater effect on maraviroc pharmacokinetics.

Regarding other agents commonly used in the treatment of patients with HIV infection, the CYP3A4 inducer rifampin decreased maraviroc exposure $\left(\mathrm{C}_{\max }\right.$ and $\left.\mathrm{AUC}\right)$ (85). The CYP3A4/P-gp inhibitor ketoconazole increased maraviroc exposure $\left(\mathrm{C}_{\max }\right.$ and $\left.\mathrm{AUC}\right)$ (86). The manufacturer recommends a maraviroc dose adjustment to $600 \mathrm{mg}$ bid with rifampin coadministration, and to $150 \mathrm{mg}$ bid with ketoconazole coadministration. Maraviroc had no clinically significant effect on the pharmacokinetics of midazolam (87), ethinylestradiol (88) or levonorgestrel (27).

Other potent CYP3A4/P-gp inducers such as phenytoin, carbamazepine and phenobarbital have not been studied when coadministered with maraviroc, but reduced exposure to maraviroc is expected with these agents, as has been noted for other potent CYP3A4/P-gp inducers. The potent CYP3A4 inhibitors clarithromycin, telithromycin, itraconazole and nefazadone are expected to increase exposure to maraviroc.

Drug interactions are summarized in the manufacturer's product monograph (27). The manufacturer recommends maraviroc dose reduction to $150 \mathrm{mg}$ bid if the concomitant treatment includes a potent CYP3A4 inhibitor, eg, HIV protease inhibitors with or without ritonavir (except tipranavir/ ritonavir). If concomitant treatment includes a CYP3A4 inducer but not a CYP3A4 inhibitor (eg, efavirenz), then an increased maraviroc dose of $600 \mathrm{mg}$ bid is recommended.

Key findings: Potent CYP3A4/P-gp inducers and inhibitors significantly influence maraviroc pharmacokinetics, and appropriate dose adjustments of maraviroc are necessary to correct maraviroc exposures.

\section{CONCLUSIONS}

Maraviroc is the first ARV agent of the CCR5 inhibitor class to be available. As an active agent in an ARV regimen, it contributes to the reduction of viral load and increased CD4 cell counts in treatment-experienced patients with R5 virus, based on up to 96 and 48 weeks of treatment, respectively, with no evidence of an increased incidence of adverse effects. Maraviroc is well tolerated and safe for up to 96 weeks; longer-term safety is under investigation. In vitro data suggest that cross-resistance with other agents in the CCR 5 inhibitor class may not be an issue, but further research is necessary. Other issues that require further investigation include the mechanism and clinical 
TABLE 5

Summary of HIV antiretroviral drug interactions with maraviroc $(27,84-86,89-96)$

\begin{tabular}{|c|c|c|c|c|c|}
\hline HIV antiviral & Dose & Maraviroc dose & $\mathbf{n}$ & $\begin{array}{c}\text { Maraviroc AUC } \\
\text { change, } \%\end{array}$ & $\begin{array}{c}\text { Maraviroc dose } \\
\text { adjustment required* }\end{array}$ \\
\hline \multicolumn{6}{|l|}{ Unboosted protease inhibitors } \\
\hline Atazanavir & $400 \mathrm{mg}$ od & $300 \mathrm{mg}$ bid & 12 & $\uparrow 257$ & $150 \mathrm{mg}$ bid \\
\hline Ritonavir & 100 mg bid & 100 mg bid & 8 & $\uparrow 161$ & $150 \mathrm{mg}$ bid \\
\hline Saquinavir & 1200 mg tid & $100 \mathrm{mg}$ bid & $12^{\dagger}$ & $\uparrow 425$ & $150 \mathrm{mg}$ bid \\
\hline \multicolumn{6}{|l|}{ Boosted protease inhibitors } \\
\hline Atazanavir/ritonavir & $300 \mathrm{mg} / 100 \mathrm{mg}$ od & 300 mg bid & 12 & $\uparrow 388$ & $150 \mathrm{mg}$ bid \\
\hline Darunavir/ritonavir & $600 \mathrm{mg} / 100 \mathrm{mg}$ bid & $150 \mathrm{mg}$ bid & $12^{\dagger}$ & $\uparrow 405$ & $150 \mathrm{mg}$ bid \\
\hline Lopinavir/ritonavir & $400 \mathrm{mg} / 100 \mathrm{mg}$ bid & $300 \mathrm{mg}$ bid & 11 & $\uparrow 283$ & $150 \mathrm{mg}$ bid \\
\hline Saquinavir/ritonavir & $1000 \mathrm{mg} / 100 \mathrm{mg}$ bid & $100 \mathrm{mg}$ bid & 11 & $\uparrow 732$ & $150 \mathrm{mg}$ bid \\
\hline Tipranavir/ritonavir & $500 \mathrm{mg} / 200 \mathrm{mg}$ bid & 150 mg bid & $12^{\dagger}$ & $\uparrow 2$ & None \\
\hline \multicolumn{6}{|l|}{ Nucleoside reverse transcriptase inhibitors } \\
\hline Lamivudine & 150 mg bid & $300 \mathrm{mg}$ single dose & NA & NA & None \\
\hline Tenofovir & $300 \mathrm{mg}$ od & $300 \mathrm{mg}$ bid & $11^{\dagger}$ & $\uparrow 3$ & None \\
\hline Zidovudine & 300 mg bid & $300 \mathrm{mg}$ bid & NA & NA & None \\
\hline \multicolumn{6}{|l|}{ Non-nucleoside reverse transcriptase inhibitors } \\
\hline Efavirenz & $600 \mathrm{mg}$ od & $100 \mathrm{mg}$ bid & $24^{\dagger}$ & $\downarrow 51$ & $600 \mathrm{mg}$ bid \\
\hline Etravirine & $200 \mathrm{mg}$ bid & $300 \mathrm{mg}$ bid & $14^{\dagger}$ & $\downarrow 53$ & $600 \mathrm{mg}$ bid \\
\hline \multicolumn{6}{|l|}{ Integrase inhibitors } \\
\hline Elvitegravir/ritonavir & $125 \mathrm{mg} / 100 \mathrm{mg}$ od & $150 \mathrm{mg}$ bid & $28^{\dagger}$ & $\uparrow 185$ & $150 \mathrm{mg}$ \\
\hline Raltegravir & $400 \mathrm{mg}$ bid & $300 \mathrm{mg}$ bid & $17^{\dagger}$ & $\downarrow 14$ & None \\
\hline \multicolumn{6}{|l|}{ ARV combination - CYP3A4 inducers } \\
\hline Nevirapine/lamivudine/tenofovir & $200 \mathrm{mg} / 150 \mathrm{mg} \mathrm{bid} / 300 \mathrm{mg}$ od & $300 \mathrm{mg}$ single dose & NA & $\uparrow 0.5$ & None \\
\hline \multicolumn{6}{|c|}{ ARV combinations - CYP3A4 inducers and inhibitors } \\
\hline Efavirenz/Combivir ${ }^{\ddagger}$ (lamivudine/zidovudine) & $600 \mathrm{mg} \mathrm{od} / 150 \mathrm{mg} / 300 \mathrm{mg}$ bid & $300 \mathrm{mg}$ single dose & NA & $\downarrow 53$ & $600 \mathrm{mg}$ bid \\
\hline Efavirenz/didanosine/tenofovir & $600 \mathrm{mg} / 250 \mathrm{mg} / 300 \mathrm{mg}$ od & $300 \mathrm{mg}$ single dose & NA & $\downarrow 52$ & $600 \mathrm{mg}$ bid \\
\hline Etravirine/darunavir/ritonavir & $200 \mathrm{mg} / 600 \mathrm{mg} / 100 \mathrm{mg}$ bid & $150 \mathrm{mg}$ bid & $14^{\dagger}$ & $\uparrow 210$ & $150 \mathrm{mg}$ bid \\
\hline Lopinavir/ritonavir (Kaletra $\left.{ }^{\S}\right) /$ efavirenz & $400 \mathrm{mg} / 100 \mathrm{mg} \mathrm{bid/600} \mathrm{mg} \mathrm{od}$ & $300 \mathrm{mg}$ bid & $12^{\dagger}$ & $\uparrow: \%$ NA & $150 \mathrm{mg}$ bid \\
\hline Lopinavir/ritonavir (Kaletra)/stavudine/lamivudine & $400 \mathrm{mg} / 40 \mathrm{mg} / 150 \mathrm{mg}$ bid & $300 \mathrm{mg}$ single dose & NA & $\uparrow 185 \%$ & $150 \mathrm{mg}$ bid \\
\hline Saquinavir/ritonavir/efavirenz & $1000 \mathrm{mg} / 100 \mathrm{mg} \mathrm{bid} / 600 \mathrm{mg}$ od & $100 \mathrm{mg}$ bid & $12^{\dagger}$ & $\uparrow: \%$ NA & $150 \mathrm{mg}$ bid \\
\hline
\end{tabular}

${ }^{*}$ In the absence of other potent cytochrome P450 3A4 (CYP3A4) inhibitors or inducers, as recommended by the manufacturer; ${ }^{\dagger}$ Healthy volunteers; ${ }^{\ddagger}$ ViiV Healthcare (USA); §Abbott Laboratories, USA. $\downarrow$ Decrease; $\uparrow$ Increase; ARV Antiretroviral; AUC Area under the plasma concentration versus time curve; bid Twice daily; NA Not available from publications of pharmacokinetic data; od Once daily; tid Three times daily

significance of maraviroc's CD4 cell count effects, its efficacy in nonclade B HIV-1 infection, the safety of maraviroc in pregnancy and its use to prevent mother-to-child transmission, the use of maraviroc in children, its role in HIV-2 infection, the clinical implications of the relatively high genital tract concentration of maraviroc, and maraviroc's potential role as a microbicide and for postexposure prophylaxis of HIV-1 infection.

Maraviroc is a new treatment option available to physicians for treatment-experienced HIV-infected adults. The present guidelines have been developed to assist health care providers in the optimal use of this new agent.

\section{RECOMMENDATIONS}

- Maraviroc is recommended for treatment-experienced patients with CCR5-tropic HIV-1 resistant to multiple ARV agents, in combination with at least two other active agents (AI).

- Raltegravir, etravirine and darunavir/ritonavir were not included in the optimized background regimen in maraviroc clinical trials, but may be considered for use concomitant with maraviroc (CIII).

- Viral tropism testing should be conducted as close to as possible or before initiation of maraviroc therapy to accurately determine viral tropism at start of treatment (AII).

- Maraviroc should not be used in patients who have failed treatment with another CCR5 antagonist (BIII).

- Current efficacy data for the use of maraviroc in treatment-naive patients are inconclusive and, therefore, the use of maraviroc in these patients cannot currently be recommended (BI).

- Resistance testing for maraviroc is not currently available nor recommended (AIII).

- Drug interactions should be taken into account when selecting the agent and dose for therapy concomitant with maraviroc (AII). The manufacturer's recommendations should be consulted, as well as a pharmacist expert in HIV treatment if available (AIII).

- The safety profile of maraviroc to date indicates that its use is not precluded in most patient populations due to safety issues, except for hypersensitivity to components of its formulation (AII).

- Caution should be used in coadministering drugs (such as CYP3A4 inducers) that require maraviroc to be used at the higher $600 \mathrm{mg}$ bid dose, if also coadministered with drugs that cause postural hypotension, or in patients with a history of postural hypotension (AIII). 
- Until data become available, maraviroc should not be used in pediatric patients younger than 16 years of age, in pregnant women or in breastfeeding women unless the potential benefits outweigh the risks (AIII).

ACKNOWLEDGEMENTS: The workshop and the development of the guidelines were supported by an unrestricted grant from Pfizer Canada Inc. The authors thank the following physicians for their valuable input into these guidelines: Jonathan Angel, JeanGuy Baril, Ken Kasper and Benoit Trottier. The authors also thank Ursula Jorch of Jorch Consulting Inc (Toronto, Ontario) for assistance in manuscript editing and preparation, financial support for which was provided by Pfizer Canada Inc. Cécile Tremblay receives funding as a Scholar with the Fonds de Recherche en Santé du Québec, and is the University of Montreal/Pfizer Chair in Clinical and Translational Research on HIV. Sharon Walmsley is the recipient of a career scientist award from the Ontario HIV Treatment Network.

SOURCE OF SUPPORT AND DISCLAIMER: The process for development of these guidelines was supported by a grant from Pfizer Canada. The views and opinions contained herein are those of the authors and do not necessarily reflect the views and opinions of Pfizer Canada.

\section{REFERENCES}

1. Panel on Antiretroviral Guidelines for Adult and Adolescents. Guidelines for the use of antiretroviral agents in HIV-infected adults and adolescents. Department of Health and Human Services, 2009:1-168. <www.aidsinfo.nih.gov/ContentFiles/

AdultandAdolescentGL.pdf> (Accessed on March 29, 2010).

2. Hammer SM, Eron JJ Jr, Reiss P, et al. Antiretroviral treatment of adult HIV infection: 2008 recommendations of the International AIDS Society - USA panel. JAMA 2008;300:555-70.

3. Moore JP, Doms RW. The entry of entry inhibitors: A fusion of science and medicine. Proc Natl Acad Sci USA 2003;100:10598-602.

4. Shaheen F, Collman RG. Co-receptor antagonists as HIV-1 entry inhibitors. Curr Opin Infect Dis 2004;17:7-16.

5. Westby M, van der Ryst E. CCR5 antagonists:

Host-targeted antivirals for the treatment of HIV infection. Antivir Chem Chemother 2005;16:339-54.

6. Moyle GJ, Wildfire A, Mandalia S, et al. Epidemiology and predictive factors for chemokine receptor use in HIV-1 infection. J Infect Dis 2005;191:866-72.

7. Kuhmann SE, Moore JP. The HIV-1 phenotypic variants - deadly and deadlier. J Viral Entry 2005;1:4-16.

8. Moore JP, Kitchen SG, Pugach P, et al. The CCR5 and CXCR4 co-receptors - central to understanding the transmission and pathogenesis of human immunodeficiency virus type 1 infection. AIDS Res Hum Retrovir 2004:20:111-26.

9. Poveda E, Briz V, Quinones-Mateu M, et al. HIV tropism: Diagnostic tools and implications for disease progression and treatment with entry inhibitors. AIDS 2006;20:1359-67.

10. Pickford C. The science of CCR 5 inhibition. The Society for General Microbiology - 160th Meeting. Manchester, March 26 to 29, 2007. (Abst)

11. Brumme ZL, Goodrich J, Mayer HB, et al. Molecular and clinical epidemiology of CXCR4-using HIV-1 in a large population of antiretroviral-naive individuals. J Infect Dis 2005;192:466-74.

12. Demarest J, Bonny T, Vavro C, et al. HIV-1 co-receptor tropism in treatment naive and experienced patients. The 44th Interscience Conference on Antimicrobial Agents and Chemotherapy (ICAAC). Washington, October 30 to November 2, 2004. (Abst)

13. Coakley E, Benhamida J, Chappey C, et al. An evaluation of tropism profiles and other characteristics among 3988 individuals screened for the A4001026, A4001027 (MOTIVATE 1) and A4001028 (MOTIVATE 2) Phase 2b/3 studies of maraviroc. The 2nd International Workshop on Targeting HIV Entry. Boston, October 20 to 21, 2006. (Abst)
14. Wilkin TJ, Su Z, Kuritzkes DR, et al. HIV type 1 chemokine co-receptor use among antiretroviral-experienced patients screened for a clinical trial of a CCR 5 inhibitor: AIDS Clinical Trial Group A5211. Clin Infect Dis 2007;44:591-5.

15. Agrawal L, Lu X, Qingwen J, et al. Role for CCR $5 \Delta 32$ protein in resistance to R5, R5X4, and X4 human immunodeficiency virus type 1 in primary CD4+ cells. J Virol 2004;78:2277-87.

16. Samson M, Libert F, Doranz BJ, et al. Resistance to HIV-1 infection in Caucasian individuals bearing mutant alleles of the CCR-5 chemokine receptor gene. Nature 1996;382:722-5.

17. Liu R, Paxton WA, Choe S, et al. Homozygous defect in HIV-1 co-receptor accounts for resistance of some multiply-exposed individuals to HIV-1 infection. Cell 1996;86:367-77.

18. McNicholl JM, Smith DK, Qari SH, et al. Host genes and HIV: The role of the chemokine receptor gene CCR 5 and its allele ( $\triangle 32$ CCR5). Emerg Infect Dis 1997;3:261-71.

19. Wu L, Paxton WA, Kassam N, et al. CCR5 levels and expression pattern correlate with infectability by macrophage-tropic HIV-1, in vitro. J Exp Med 1997;185:1681-91.

20. Glass WG, McDermott DH, Lim JK, et al. CCR5 deficiency increases risk of symptomatic West Nile virus infection. J Exp Med 2006;203:35-40.

21. Eugen-Olsen J, Iversen AKN, Garret P, et al. Heterozygosity for a deletion in the CKR-5 gene leads to prolonged AIDS-free survival and slower CD4 T-cell decline in a cohort of HIV-seropositive individuals. AIDS 1997;11:305-10.

22. Westby M, Smith-Burchnell C, Mori J, et al. Reduced maximal inhibition in phenotypic susceptibility assays indicates that viral strains resistant to the CCR5 antagonist maraviroc utilize inhibitor-bound receptor for entry. J Virol 2007;81:2359-71.

23. Hitchcock C. Discovery \& exploratory development of maraviroc (UK-427,857) a CCR5 antagonist for the treatment of HIV/AIDS. The 2005 International Meeting of the Institute of Human Virology. Baltimore, August 29 to September 2, 2005. (Abst)

24. Lewis M. Bioinformatic support for the development of the CCR5 antagonist maraviroc (UK-427,857). InfoTech for Pharma \& Biotech. London, March 12 to 15, 2007. (Abst)

25. Dorr P, Westby M, Dobbs S, et al. Maraviroc (UK-427,857), a potent, orally bioavailable, and selective small-molecule inhibitor of chemokine receptor CCR5 with broad-spectrum anti-human immunodeficiency virus type 1 activity. Antimicrob Agents Chemother 2005;49:4721-32.

26. Ayoub A, van der Ryst, Turner K, et al. A review of the markers of immune function during the maraviroc Phase 1 and 2a studies. The 14th Conference on Retroviruses and Opportunistic Infections (CROI). Los Angeles, February 25 to 28, 2007. (Abst)

27. Celsentri Package Insert. Pfizer Inc, 2007.

28. Saag M, Goodrich J, Fatkenheuer G, et al. A double-blind, placebo-controlled trial of maraviroc in treatment-experienced patients infected with non-R5 HIV-1. J Infect Dis 2009;199:1638-47.

29. Swenson L, Dong W, Mo T, et al. Quantification of HIV tropism by "deep" sequencing shows a broad distribution of prevalence of X4 variants in clinical samples that is associated with virological outcome. The 16th Conference on Retroviruses and Opportunistic Infections (CROI). Montreal, February 8 to 11,2009 . (Abst)

30. Van der Ryst E, Westby M. Changes in HIV-1 co-receptor tropism for patients participating in the maraviroc MOTIVATE 1 and 2 clinical trials. The 47th Interscience Conference on Antimicrobial Agents and Chemotherapy (ICAAC). Chicago, September 17 to 20, 2007. (Abst)

31. Asmuth D, Goodrich J, Cooper D, et al. CD4 cell restoration after 48 weeks in the maraviroc treatment-experienced trials MOTIVATE 1 and 2. The XVII International AIDS Conference. Mexico City, August 3 to 8, 2008. (Abst)

32. Heera J, Saag M, Ive P, et al. Virological correlates associated with treatment failure at week 48 in the Phase 3 study of maraviroc in treatment-naive patients. The 15th Conference on Retroviruses and Opportunistic Infections. Boston, February 3 to 5, 2008. (Abst)

33. Valdez H, Lewis M, Delogne C, et al. Weighted OBT susceptibility score (wOBTSS) is a stronger predictor of virologic response at 48 weeks than baseline tropism result in MOTIVATE 1 and 2. The 48th Interscience Conference on Antimicrobial Agents and Chemotherapy (ICAAC). Washington, October 25 to 28, 2008. (Abst)

34. Clax P, Rajicic N, Westby M, et al. Association between HIV-1 co-receptor tropism results and clinical and laboratory factors in 
3,862 patients screened for phase 3 clinical studies of maraviroc. The 3rd International Workshop on Targeting HIV Entry. Washington, December 7 to 8, 2007. (Abst)

35. Fatkenheuer G, Nelson M, Lazzarin A, et al. Subgroup analyses of maraviroc in previously treated R5 HIV-1 infection.

New Engl J Med 2008;359:1442-55.

36. Lazzarin A, Battegay M, Cooper DA, et al. CD4+ cell increases at 48 weeks in the maraviroc treatment-naïve MERIT trial. The 48th Interscience Conference on Antimicrobial Agents and Chemotherapy (ICAAC). Washington, October 25 to 28, 2008. (Abst)

37. Gulick RM, Lalezari J, Goodrich J, et al. Maraviroc for previously treated patients with R5 HIV-1 infection. New Engl J Med 2008;359:1429-41.

38. Hardy WD, Gulick R, Mayer H, et al. Efficacy and safety of maraviroc in treatment-experienced patients infected with R5 HIV-1: 96-week combined analysis of the MOTIVATE 1 and 2 studies. The 9th International Congress on Drug Therapy in HIV Infection. Glasgow, November 9 to 13, 2008. (Abst)

39. Nelson M, Fisher M, Gonzalez-Garcia J, et al. Impact of baseline antiretroviral resistance status on efficacy outcomes among patients receiving maraviroc plus an optimized background therapy (OBT) versus placebo plus OBT in the MOTIVATE 1 and 2 trials. The XVII International AIDS Conference. Mexico City, August 3 to 8, 2008. (Abst)

40. Eng RHK, Perez G, Paez SL, et al. Impact of adding maraviroc to HIV patients with undetectable plasma RNA but are non-CD4 progressors (CD4 $200 \mathrm{cell} / \mathrm{mm}^{3}$. The 48th Interscience Conference on Antimicrobial Agents and Chemotherapy (ICAAC). Washington, October 25 to 28, 2008. (Abst)

41. Lazzarin A, Clotet B, Cooper D, et al. Efficacy of enfuvirtide in patients infected with drug-resistant HIV-1 in Europe and Australia. N Engl J Med 2003;348:2186-95.

42. Lalezari JP, Henry K, O'Hearn M, et al. Enfuvirtide, an HIV-1 fusion inhibitor, for drug-resistant HIV infection in North and South America. N Engl J Med 2003;348:2175-85.

43. Clotet B, Bellos N, Molina J-M, et al. Efficacy and safety of darunavir-ritonavir at week 48 in treatment-experienced patients with HIV-1 infection in POWER 1 and 2: A pooled subgroup analysis of data from two randomised trials. Lancet 2007;369:1169-78.

44. Hicks CB, Cahn P, Cooper DA, et al. Durable efficacy of tipranavir-ritonavir in combination with an optimised background regimen of antiretroviral drugs for treatment-experienced HIV-1-infected patients at 48 weeks in the Randomized Evaluation of Strategic Intervention in multi-drug resistant patients with Tipranavir (RESIST) studies: An analysis of combined data from two randomised open-label trials. Lancet 2006;368:466-75.

45. Cooper DA, Steigbigel RT, Gatell JM, et al. Subgroup and resistance analyses of raltegravir for resistant HIV-1 infection. N Engl J Med 2008;359:355-65.

46. Steigbigel RT, Cooper DA, Kumar PN, et al. Raltegravir with optimized background therapy for resistant HIV-1 infection. N Engl J Med 2008;359:339-54.

47. Gulick RM, van der Ryst E, Lampiris H, et al. Efficacy and safety of once-daily (OD) compared with twice-daily (BID) maraviroc plus optimized background therapy (OBT) in treatment-experienced patients infected with CCR5-tropic HIV-1: 24-week combined analysis of the MOTIVATE 1 and 2 studies. The 4th IAS Conference on HIV Pathogenesis, Treatment and Prevention. Sydney, July 22 to 25,2007 . (Abst)

48. McFayden L, Jacqmin P, Wade JR, et al. Maraviroc (MVC) exposure-efficacy relationship in treatment-experienced HIV-1infected patients. The 11th European AIDS Conference/EACS. Madrid, October 24 to 27, 2007. (Abst)

49. Weatherley B, McFayden L, Chan PLS, et al. Population pharmacokinetic covariate analysis of maraviroc in phase $2 b / 3$ studies in treatment experienced (TE) HIV-1 infected patients on optimized background therapy (OBT). The 9th International Workshop on Clinical Pharmacology of HIV Therapy. New Orleans, April 9, 2008. (Abst)

50. Fatkenheuer G, Pozniak AL, Johnson MA, et al. Efficacy of short-term monotherapy with maraviroc, a new CCR5 antagonist, in patients infected with HIV-1. Nat Med 2005;11:1170-2.

51. Van der Ryst E, Fatkenheuer G, Pozniak A, et al. Maraviroc (UK-427,857), a novel CCR5 antagonist, demonstrates antiviral activity during 10-day monotherapy studies. The 1st International
Workshop on Targeting HIV Entry. Baltimore, December 2 to 3, 2005. (Abst)

52. Saag M, Ive P, Heera J, et al. A multicenter, randomized, double-blind, comparative trial of a novel CCR 5 antagonist, maraviroc versus efavirenz, both in combination with Combivir (zidovudine/ lamivudine), for the treatment of antiretroviral-naïve patients infected with R5 HIV-1: Week 48 results of the MERIT study. The 4th International AIDS Conference. Sydney, July 22 to 25, 2007. (Abst)

53. Saag M, Heera J, Goodrich J, et al. Reanalysis of the MERIT study with the Enhanced Trofile assay (MERIT-ES). The 48th Interscience Conference on Antimicrobial Agents and Chemotherapy (ICAAC). Washington, October 25 to 28, 2008. (Abst)

54. McFayden L, Jacqmin P, Wade JR, et al. Maraviroc exposure-efficacy $(<50$ copies $/ \mathrm{mL})$ analysis in HIV-1-infected treatment-naïve patients - ITT population (MERIT study). The XVII International AIDS Conference (IAC). Mexico City, August 3 to 8, 2008. (Abst)

55. McGovern R, Dong W, Zhong X, et al. Population-based sequencing of the V3-loop is comparable to the enhanced sensitivity Trofile assay in predicting virologic response to maraviroc of treatment-naive patients in the MERIT trial. The 17th Conference on Retroviruses and Opportunistic Infections. San Francisco, February 16 to 19, 2010. (Abst)

56. Lewis M, Mori J, Simpson P, et al. Changes in V3 loop sequence associated with failure of maraviroc treatment in patients enrolled in the MOTIVATE 1 and 2 trials. The 15th Conference on Retroviruses and Opportunistic Infections (CROI). Boston, February 3 to 6, 2008. (Abst)

57. Mosley M, Smith-Burchnell C, Mori J, et al. Resistance to the CCR 5 antagonist maraviroc is characterised by dose response curves that display a reduction in maximal inhibition (plateau). The 13th Conference on Retroviruses and Opportunistic Infections (CROI). Denver, February 5 to 9, 2006. (Abst)

58. Lewis M, Westby M, Smith-Buchnell C, et al. A genotypic analysis of HIV-1 sequences from emerging resistant virus after in vitro serial passage with CCR5 antagonist maraviroc (UK-427,857). The 3rd European HIV Drug Resistance Workshop. Athens, March 30 to April 1, 2005. (Abst)

59. Jubb B, Lewis M, Simpson P, et al. CCR5-tropic resistance to maraviroc is uncommon even among patients on functional maraviroc monotherapy or with ongoing low-level replication. The 16th Conference on Retroviruses and Opportunistic Infections (CROI). Montreal, February 8 to 11, 2009. (Abst)

60. Lewis M, van der Ryst E, Youle M, et al. Phylogenetic analysis and co-receptor tropism of HIV-1 envelope sequences from two patients with emergence of CXCR4 using virus following treatment with the CCR5 antagonist UK-427,857. The 44th Interscience Conference on Antimicrobial Agents and Chemotherapy (ICAAC). Washington, October 30 to November 2, 2004. (Abst)

61. Westby M, Lewis M, Whitcomb J, et al. Emergence of CXCR4-using human immunodeficiency virus type 1 (HIV-1) variants in a minority of HIV-1-infected patients following treatment with the CCR 5 antagonist maraviroc is from a pretreatment CXCR4-using virus reservoir. J Virol 2006;80:4909-20.

62. Archer J, Braverman M, Taillon B, et al. Ultra-deep sequencing for detecting minority virus: Implications for ART. The 16th Conference on Retroviruses and Opportunistic Infections (CROI). Montreal, February 8 to 11, 2009. (Abst)

63. Lewis M, Simpson P, Fransen S, et al. CXCR4-using virus detected in patients receiving maraviroc in the phase 3 studies MOTIVATE 1 and 2 originates from a pre-existing minority of CXCR4-using virus. The XVI International HIV Drug Resistance Workshop. Barbados, June 12 to 16,2007 . (Abst)

64. Waters L, Scourfield A, Marcano M, et al. The evolution of co-receptor tropism in patients interrupting suppressive HAART. The 16th Conference on Retroviruses and Opportunistic Infections (CROI). Montreal, February 8 to 11, 2009. (Abst)

65. Deeks SG, Hoh R, Neilands TB, et al. Interruption of treatment with individual therapeutic drug classes in adults with multidrug-resistant HIV-1 infection. J Infect Dis 2005;192:1537-44.

66. Deeks SG, Lu J, Hoh R, et al. Interruption of enfuvirtide in HIV-1-infected adults with incomplete viral suppression on an enfuvirtide-based regimen. J Infect Dis 2007;195:387-91.

67. Trinh L, Han D, Huang W, et al. Validation of an enhanced sensitivity Trofile ${ }^{\mathrm{TM}}$ HIV-1 co-receptor tropism assay. The 48th Interscience Conference on Antimicrobial Agents and Chemotherapy (ICAAC). Washington, October 25 to 28, 2008. (Abst) 
68. Trofile Co-Receptor Tropism Assay. What is Trofile. $<$ www.trofileassay.com/what_is_trofile.html $>$ (Accessed on March 29, 2010).

69. Harrigan R. Predicting response to CCR5 antagonists. The 16th Conference on Retroviruses and Opportunistic Infections (CROI). Montreal, February 8 to 11, 2009. (Abst)

70. Ayoub A, Goodrich J, van der Ryst, et al. Adverse event profile of maraviroc in treatment-experienced patients infected with R5 HIV-1. The 48th Interscience Conference on Antimicrobial Agents and Chemotherapy (ICAAC). Washington, October 25 to 28, 2008. (Abst)

71. Nichols WG, Steel HM, Bonny T, et al. Hepatotoxicity observed in clinical trials of aplaviroc (GW873140). Antimicrob Agents Chemother 2008;52:858-65.

72. Hoepelman IM, Ayoub A, Heera J, et al. The incidence of severe liver enzyme abnormalities and hepatic adverse events in the maraviroc clinical development programme. The 11th European AIDS Conference (EACS). Madrid, October 24 to 27, 2007. (Abst)

73. Gulick RM, Su Z, Flexner C, et al. Phase 2 study of the safety and efficacy of vicriviroc, a CCR5 inhibitor, in HIV-1-infected, treatment-experienced patients: AIDS Clinical Trials Group 5211. J Infect Dis 2007;196;304-12.

74. Maguire JJ, Kuc RE, Katugampola SD, et al. Novel function of the inflammatory chemokine MIP-1 $\exists$, a ligand for the HIV co-receptor CCR5, as a vasoconstrictor of human blood vessels: Antagonism by maraviroc. The Annual Scientific Meeting of the British Hypertension Society. Cambridge, September 24 to 26, 2007. (Abst)

75. McHale M, Abel S, Russell D, et al. Overview of phase 1 and 2a safety and efficacy data of maraviroc (UK-427,857). The 3rd IAS Conference on HIV Pathogenesis and Treatment. Rio de Janeiro, July 24 to 27, 2005. (Abst)

76. Russell D, Weissgerber G, Wooldridge $\mathrm{C}$, et al. Investigation into the haemodynamic effects of oral maraviroc (UK-427,587) in healthy volunteers. The 10th European AIDS Conference (EACS). Dublin, November 17 to 20, 2005. (Abst)

77. Davis J, Hackman F, Sudworth D, et al. A single dose study to investigate the effect of the CCR 5 antagonist maraviroc (UK-427,587) on the QTc interval in healthy patients. The 6th International Workshop on Clinical Pharmacology of HIV Therapy. Quebec, April 26 to 29, 2005. (Abst)

78. DeJesus E, Walmsley S, Cohen C, et al. Fasted lipid changes after administration of maraviroc or efavirenz in combination with zidovudine and lamivudine (Combivir) for 48 weeks to treatment-naïve HIV-infected patients. The 15th Conference on Retroviruses and Opportunistic Infections (CROI). Boston, February 3 to 6, 2008. (Abst)

79. Ayoub A, Goodrich J, Tressler R, et al. Incidence of infections in treatment-experienced patients infected with R5 HIV-1 in the MOTIVATE studies of maraviroc in combination with optimized background therapy. The 9th International Congress on Drug Therapy in HIV Infection. Glasgow, November 9 to 13, 2008. (Abst)

80. American Academy of Pediatrics, Pediatric Care Online. FDA Pregnancy Categories. < http://www.pediatriccareonline.org/pco/ub/ view/Pediatric-Drug-Lookup/153860/0/FDA_Pregnancy_Categories> (Accessed on March 29, 2010).

81. Abel S, Ridgway C, Hamlin J, et al. An open, parallel group study to compare the pharmacokinetics, safety and toleration of a single oral dose of maraviroc in patients with mild and moderate hepatic impairment with patients with normal hepatic function. The 8th International Workshop on Clinical Pharmacology of HIV Therapy. Budapest, April 16 to 18, 2007. (Abst)

82. Fatkenheuer G, Pozniak A, Johnson M, et al. Evaluation of dosing frequency and food effect on viral load reduction during short-term monotherapy with UK-427,857, a novel CCR5 antagonist. The 15th International AIDS Conference. Bangkok, July 11 to 16, 2004. (Abst)
83. Dumond JB, Patterson KB, Pecha A, et al.

Maraviroc pharmacokinetics in blood plasma, genital tract fluid and tissue in healthy female volunteers. The 15th Conference on Retroviruses and Opportunistic Infections (CROI). Boston, February 3 to 6, 2008. (Abst)

84. Abel S, Russell D, Ridgway C, et al. Overview of the drug-drug interaction data for maraviroc (MVC, UK-427,857). The 6th International Workshop on Clinical Pharmacology of HIV Therapy. Quebec, April 28 to 30, 2005. (Abst)

85. Jenkins T, Abel S, Russell D, et al. The effect of P450 inducers on the pharmacokinetics of CCR 5 antagonist, UK-427,857, in healthy volunteers. The 5th International Workshop on Clinical Pharmacology of HIV Therapy. Rome, April 1 to 3, 2004. (Abst)

86. Abel S, Russell D, Ridgway C, et al. Effect of CYP3A4 inhibitors on the pharmacokinetics of CCR 5 antagonist UK-427,857 in healthy volunteers. The 5th International Workshop on Clinical Pharmacology of HIV Therapy. Rome, April 1 to 3, 2004. (Abst)

87. Abel S, Russell D, Ridgway C, et al. Effect of CCR5 antagonist UK-427,857 on the pharmacokinetics of CYP3A4 substrates in healthy volunteers. The 5 th International Workshop on Clinical Pharmacology of HIV Therapy. Rome, April 1 to 3, 2004. (Abst)

88. Abel S, Whitlock L, Ridgway C, et al. Effect of UK-427,857 on the pharmacokinetics of oral contraceptive steroids, and the pharmacokinetics of UK-427,857 in healthy young women. The 43rd Interscience Conference on Antimicrobial Agents and Chemotherapy (ICAAC). Chicago, September 14 to 17, 2003. (Abst)

89. Abel S, Ridgway C, Hamlin J, et al. An open, randomized 2-way crossover study to investigate the effect of darunavir/ritonavir on the pharmacokinetics of maraviroc in healthy patients. The 8 th International Workshop on Clinical Pharmacology of HIV Therapy. Budapest, April 16 to 18, 2007. (Abst)

90. Abel S, Taylor-Worth R, Ridgway C, et al. Effect of tipranavir/ritonavir on the pharmacokinetics of maraviroc (MVC, UK-427,857). The 7th International Workshop on Clinical Pharmacology of HIV Therapy. Lisbon, April 20 to 22, 2006. (Abst)

91. Andrews E, Glue P, Fang J, et al. A pharmacokinetic study to evaluate an interaction between maraviroc and raltegravir in healthy adults. The 48th Annual ICAAC/IDSA 46th Annual Meeting. Washington, October 25 to 28,2008 . (Abst)

92. Davis J, Scholler-Gyure M, Kakuda TN, et al. An open, randomized, two-period, crossover study in two cohorts to investigate the effect of steady state TMC125 (etravirine) and the combination of TMC125/darunavir/ritonavir on the steady-state pharmacokinetics of oral maraviroc in healthy patients. The 11th European AIDS Conference (EACS). Madrid, October 24 to 27, 2007. (Abst)

93. Muirhead G, Russell D, Abel S, et al. An investigation of the effects of tenofovir on the pharmacokinetics of the novel CCR5 inhibitor UK-427,857. Seventh International Congress on Drug Therapy in HIV Infection. Glasgow, November 14 to 17, 2004. (Abst)

94. Muirhead G, Pozniak A, Gazzard B, et al. A novel probe drug interaction study to investigate the effect of selected ARV combinations on the pharmacokinetics of a single oral dose of maraviroc (UK-427,587) in HIV + ve patients. The 12th Conference on Retroviruses and Opportunistic Infections. Boston, February 22 to 25, 2005. (Abst)

95. Ramanathan S, West S, Abel S, et al. Pharmacokinetics of coadministered ritonavir-boosted elvitegravir plus maraviroc The 47th Interscience Conference on Antimicrobial Agents and Chemotherapy (ICAAC). Chicago, September 17 to 20, 2007. (Abst)

96. Russell D, Ridgway C, Mills C, et al. A study to investigate the combined co-administration of P450 CYP3A4 inhibitors and inducers on the pharmacokinetics of the novel CCR 5 inhibitor UK-427,587. The 7th International Congress on Drug Therapy in HIV Infection. Glasgow, November 14 to 18, 2004. (Abst) 


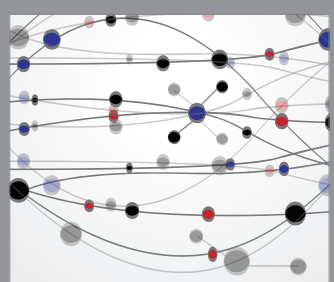

The Scientific World Journal
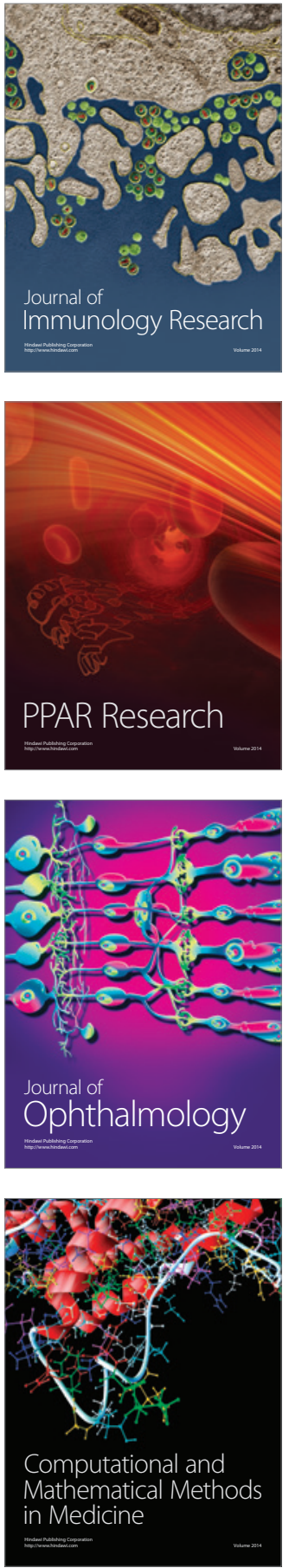

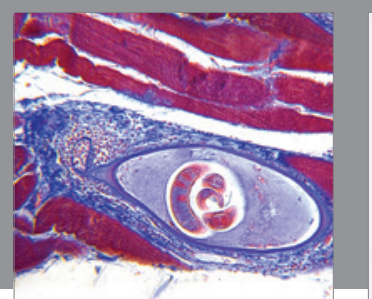

Gastroenterology Research and Practice

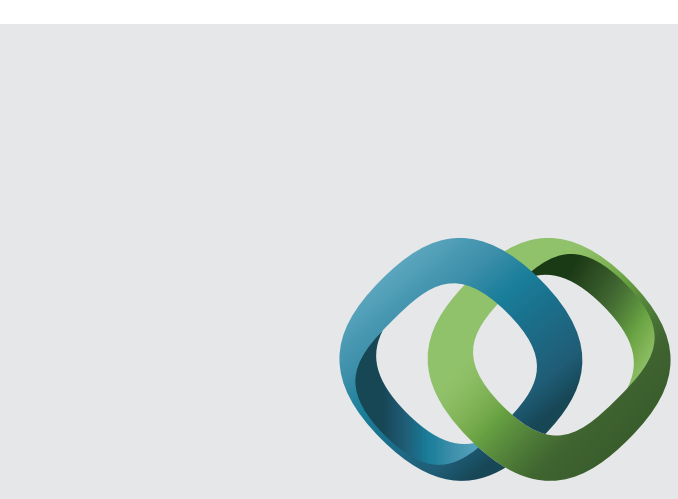

\section{Hindawi}

Submit your manuscripts at

http://www.hindawi.com
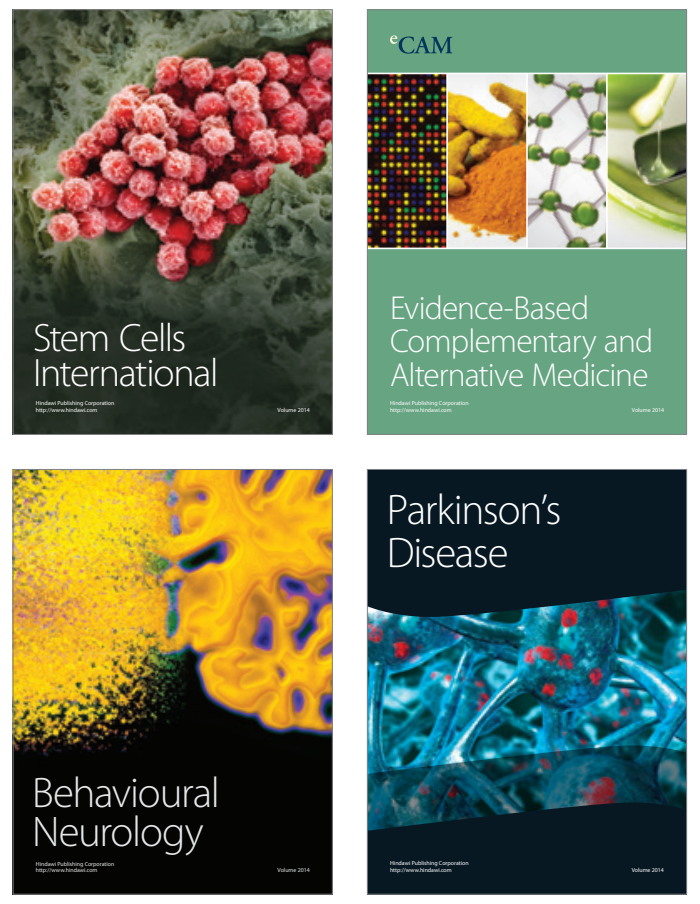
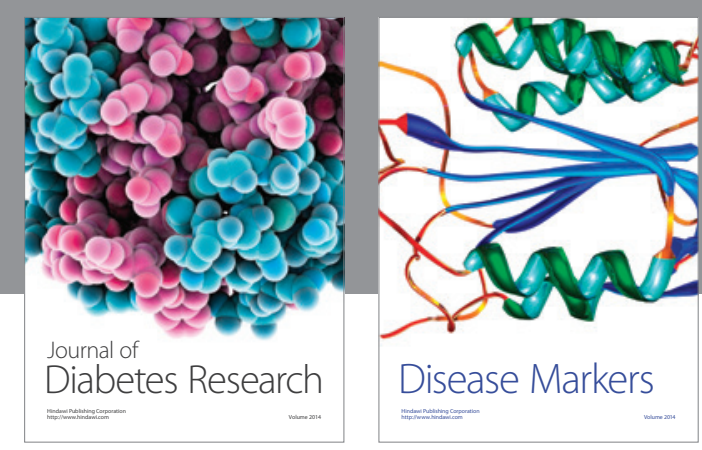

Disease Markers
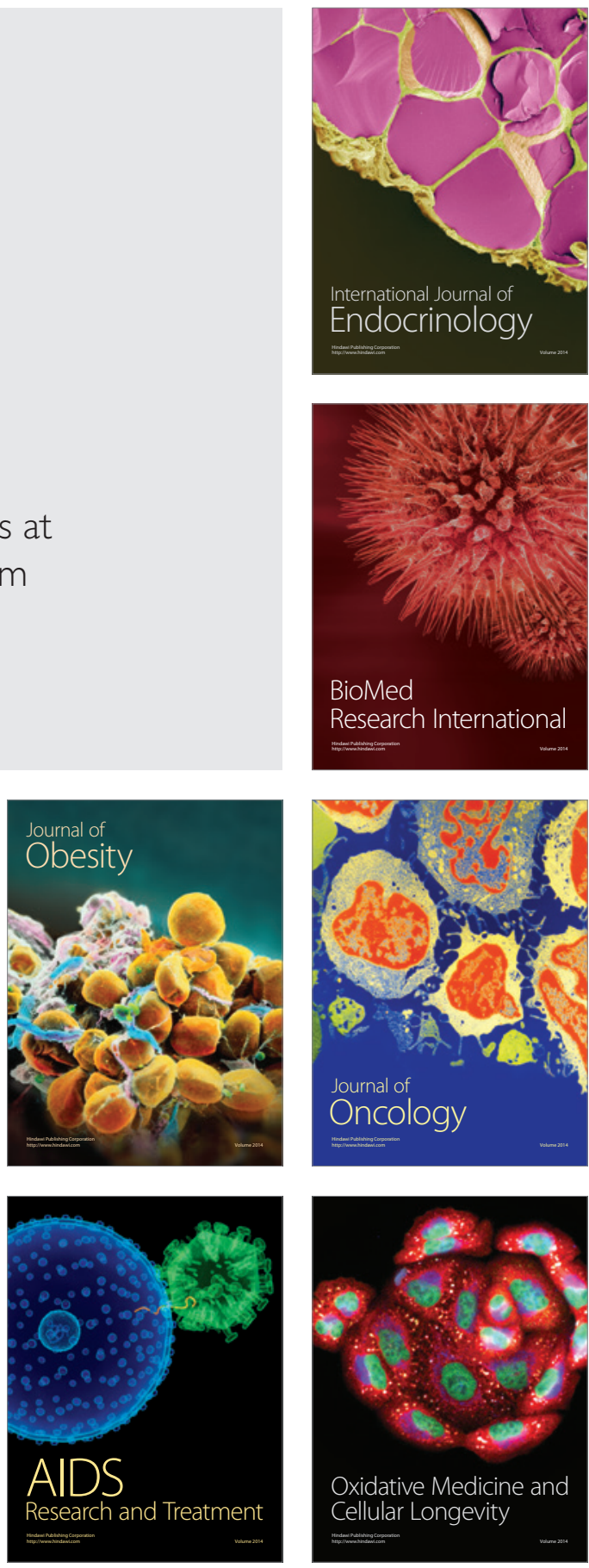